\title{
Tailored Web-Based Information for Younger and Older Patients with Cancer: Randomized Controlled Trial of a Preparatory Educational Intervention on Patient Outcomes
}

Minh Hao Nguyen ${ }^{1,2}, \mathrm{PhD}$; Ellen M A Smets ${ }^{3}, \mathrm{PhD}$; Nadine Bol ${ }^{1,4}, \mathrm{PhD}$; Eugène F Loos ${ }^{1}, \mathrm{PhD}$; Hanneke W M van Laarhoven $^{5}, \mathrm{MD}, \mathrm{PhD}$; Debby Geijsen ${ }^{6}, \mathrm{MD}$; Mark I van Berge Henegouwen ${ }^{7}, \mathrm{MD}, \mathrm{PhD}$; Kristien M A J Tytgat ${ }^{8}$, $\mathrm{MD}, \mathrm{PhD}$; Julia C M van Weert ${ }^{1}, \mathrm{PhD}$

\footnotetext{
${ }^{1}$ Amsterdam School of Communication Research, University of Amsterdam, Amsterdam, Netherlands

${ }^{2}$ Department of Communication and Media Research (IKMZ), University of Zurich, Zurich, Switzerland

${ }^{3}$ Department of Medical Psychology, Amsterdam University Medical Centers, University of Amsterdam, Amsterdam, Netherlands

${ }^{4}$ Department of Communication and Cognition, Tilburg University, Tilburg, Netherlands

${ }^{5}$ Department of Medical Oncology, Cancer Center Amsterdam, Amsterdam University Medical Centers, University of Amsterdam, Amsterdam, Netherlands

${ }^{6}$ Department of Radiation Oncology, Amsterdam University Medical Centers, University of Amsterdam, Amsterdam, Netherlands

${ }^{7}$ Department of Surgery, Cancer Center Amsterdam, Amsterdam University Medical Centers, University of Amsterdam, Amsterdam, Netherlands

${ }^{8}$ Department of Gastroenterology, Amsterdam University Medical Centers, University of Amsterdam, Amsterdam, Netherlands
}

\section{Corresponding Author:}

Minh Hao Nguyen, PhD

Amsterdam School of Communication Research

University of Amsterdam

Nieuwe Achtergracht 166, 1018 WV

Amsterdam

Netherlands

Phone: 3120525368

Email: mh.nguyen@ikmz.uzh.ch

\section{Abstract}

Background: Many patients with cancer, including older patients (aged $\geq 65$ years), consult the Web to prepare for their doctor's visit. In particular, older patients have varying needs regarding the mode in which information is presented (eg, via textual, visual, or audiovisual modes) owing to age-related sensory (eg, impaired vision and hearing) and cognitive decline (eg, reduced processing speed). Therefore, Web-based information targeted at older patient populations is likely to be used and processed more effectively, and evaluated more positively, when tailored to age-related capabilities and preferences. This, in turn, may benefit patient outcomes.

Objective: This randomized controlled trial tested the effects of a Web-based tailored educational intervention among newly diagnosed younger ( $<65$ years) and older ( $\geq 65$ years) patients with cancer. We compared the intervention group who viewed a mode-tailored website (ie, enabling patients to tailor information using textual, visual, and audiovisual modes) with 3 control groups view a nontailored website (ie, text only, text with images, and text with videos). We examined website experience outcomes (ie, website satisfaction, website involvement, knowledge, anxiety, and communication self-efficacy) and consultation experience outcomes (ie, question asking during consultation, anxiety, and information recall).

Methods: Patients from a multidisciplinary outpatient clinic ( $\mathrm{N}=232)$ viewed a mode-tailored or nontailored website as preparation before their hospital consultations to discuss diagnosis and treatment. Data were collected before (T1), during (T2), and after (T3) visitation. Website experience outcomes were assessed with questionnaires (T1). Patients' question asking was coded from videotaped consultations, and anxiety was assessed through a questionnaire (T2). Telephone interviews were conducted to assess knowledge acquired from the website before (T1) and after consultation (T3), and information recall from the consultation (T3).

Results: The preparatory website was well used across all conditions (mean $34 \mathrm{~min}$ ). Younger patients viewing the mode-tailored website were more satisfied before consultation $(P=.02)$ and reported lower anxiety after consultation $(P=.046$; vs text only). This pattern was not found in older patients. Mode tailoring yielded no other significant differences in patient outcomes. Regression 
analyses showed that website involvement (beta=.15; $P=.03$ ) and, to a lesser extent, website satisfaction (beta=.15; $P=.05$ ) positively associated with knowledge before consultation (T1). In turn, higher knowledge before consultation $($ beta $=.39 ; P<.001)$, together with time on the website (beta=.21;P=.002; T1), predicted information recall from consultations (T3). Patients with higher knowledge before consultation (T1) also reported higher knowledge from the website afterward (T3; beta=.22; $P=.003)$.

Conclusions: Offering preparatory online information before consultations benefits information processing and patient outcomes of both younger and older newly diagnosed patients with cancer. Younger patients benefit even more when information is offered in a mode-tailored manner. We discuss the theoretical, methodological, and practical implications for patient-provider communication research in an electronic health era.

Clinical Trial: Netherlands Trial Register NTR5904; https://www.trialregister.nl/trial/5750

(J Med Internet Res 2019;21(10):e14407) doi: 10.2196/14407

\section{KEYWORDS}

Web-based tailoring; internet; audiovisual media; patient education; cancer; aging; memory; anxiety; patient reported outcomes; patient participation; consultation; health communication; randomized controlled trial

\section{Introduction}

\section{Background}

Cancer often occurs in people of older age ( $\geq 65$ years), and this number is expected to grow globally [1]. Older patients with cancer constitute the majority of the cancer patient population and are also most at risk for poor communication with health care providers owing to age-related declines, such as in cognitive (eg, working memory) and physical functioning (eg, vision loss, hearing loss, and comorbidity) [2]. In general, older patients are less likely to express their information needs or preferences and participate less actively during consultations [2,3]. Moreover, they generally experience lower self-efficacy in obtaining relevant information from their provider [4] and have more difficulty remembering information from consultations than younger patients [5,6]. Therefore, particularly, older patients could benefit from support by communicating with providers. This study aimed to investigate whether tailored online health information can provide such support to older and younger patients by examining the effects on patient-reported and observed outcomes, including website satisfaction, communication self-efficacy, anxiety, question asking during consultation, and information recall.

The information society of today is characterized by the availability of and relatively easy access to cancer information on the internet. For many older adults, besides their health care provider, the internet is one of the first preferred health information sources [7]. Online health information (eg, a hospital website) is often used to prepare for a doctor's visit [7] and may lead to better informed, more confident, and less anxious patients [8,9]. Moreover, the use of preparation tools can support patients to actively participate in consultations (eg, by asking questions) and process and recall information from their health care provider $[10,11]$.

Unfortunately, many older patients experience difficulties in using online health information [12]. Although this problem could resolve itself as generations pass by and the digital divide closes, age-related sensory (eg, impaired vision and/or hearing) and cognitive decline (eg, reduced processing speed) remain a prominent reason preventing older adults from using the internet effectively $[12,13]$. Such age-related declines also explain why older adults have varying needs regarding how information should be presented, making it more challenging to develop user-friendly websites for this group $[14,15]$. Online health information distinguishes itself from traditional formats of health information (eg, print materials) because of its possibility to integrate different modalities (ie, modes), such as textual, visual, and/or audiovisual information. What is particularly relevant for older patients is that these information modes can be tailored to match individual preferences and abilities (eg, age-related factors) and thus facilitate information processing [16]. Mode tailoring refers to the possibility of individuals to adapt the modality of online information presentation to their preferences, using textual, visual, and audiovisual information [17]. Recent experimental research showed positive effects on the evaluation, processing, and recall of cancer-related information when people were able to self-tailor the mode of presentation on a health website, especially among older adults $[17,18]$. Hence, mode tailoring is a particularly promising strategy to optimize online health information for the older population.

This study extends this experimental mode tailoring research to a clinical population of newly diagnosed patients with cancer who viewed a previsit website to prepare for their hospital consultations to discuss diagnosis and treatment planning. In a randomized controlled trial (RCT), we investigated both preand postvisit effects of exposure to a previsit website that can be tailored to patients' information mode preferences (by self-selecting text, images, and/or videos) compared with exposure to standardized, nontailored websites (with either text only, text with images, or text with videos). First, we examined the effects of mode tailoring on website experience outcomes before the consultation (T1), including patients' website involvement, satisfaction with the website, anxiety, self-efficacy in communicating with the provider, and knowledge. We also investigated whether mode tailoring effects extend to the consultation and beyond. Consultation experience outcomes include patients' question-asking behavior during consultation and anxiety (T2). Additionally, we considered knowledge gained from the website and information recall after the consultation (T3). Second, for all outcomes, we investigated how these effects differ between younger and older patients. Third, across all patients, we investigated how website experiences predict knowledge before the consultation (T1) and how website 
experiences and consultation experiences predict knowledge and information recall after the consultation (T3). By looking into the interplay between online health information provision and offline patient-provider communication in the cancer context, this study has provided insights for both practice and theory regarding patient-provider communication in an electronic health (eHealth) era.

\section{Mode Tailoring: Catering to Older Patients' Motivation and Ability}

The elaboration likelihood model (ELM) and the limited capacity model of motivated mediated message processing (LC4MP) state that information processing is highly dependent on an individual's motivation (eg, attention) and ability (eg, cognitive resources) to process information [19,20]. Older adults often see themselves as less able and are less motivated to use online health information [21]. Moreover, many older adults who go online for health information are left unsatisfied [22]. A partial explanation is that many available health websites insufficiently consider age-related factors in their design [12,23]. Providing different information modes (eg, via text, visuals, and videos) in a tailored manner can increase both the motivation and ability to use and process online health information and may, therefore, be especially relevant for older users. For instance, when the mode of presentation matches with an individual's preference for how to consume online health information, this is likely to increase their motivation to attend to the information. Additionally, tailoring the mode of information presentation caters to differences in individual processing styles and abilities_-including age-related declines in vision, hearing, and cognition-which enables individuals to process the information better. Thus, when online health information is tailored to individual mode preferences, these preconditions (ie, motivation and ability) for successful processing are considered more optimal. Consequently, mode-tailored information has a greater likelihood to reach and affect patients than nontailored information, especially older patients. In the following sections, we have discussed the expected benefits of mode-tailored online health information for patient-reported outcomes surrounding a hospital visit in younger and older patients.

\section{Effects on Website Experience Outcomes Before Consultation: Involvement, Satisfaction, Anxiety, Communication Self-Efficacy, and Knowledge}

A (potential) diagnosis of cancer typically involves high levels of anxiety [24], which can hinder patients' ability to process and remember information provided by their provider [18]. Although it can be overwhelming to receive information related to the disease [25], patients have a high need for information during this uncertain phase [26]. Providing patients with mode-tailored information might enable them to absorb the information in a dosed manner (eg, by reading the text first and saving a video for later) [27]. As mode-tailored information is more accessible to patients, it is expected to be evaluated and processed better too $[17,18]$. Furthermore, viewing tailored online information before a hospital visit is likely to decrease patients' anxiety, as they are better informed and prepared for what can be expected [28]. Similarly, the use of tailored preparatory information might increase self-efficacy in communicating with the provider [29,30]. Given that mode tailoring is anticipated to cater to age-related declines, we expect that older patients will benefit more from a mode-tailored website than younger patients.

- H1: Exposure to a mode-tailored preparatory website (vs nontailored websites) will affect patients' website experience outcomes before a consultation (T1), including enhanced website involvement (H1a); enhanced website satisfaction (H1b); decreased anxiety (H1c); enhanced communication self-efficacy (H1d); and improved knowledge (H1e).

- H2: These effects will be stronger for older patients $(\geq 65$ years) than for younger patients ( $<65$ years) with regard to website involvement $(\mathrm{H} 2 \mathrm{a})$, website satisfaction $(\mathrm{H} 2 \mathrm{~b})$, anxiety $(\mathrm{H} 2 \mathrm{c})$, communication self-efficacy $(\mathrm{H} 2 \mathrm{~d})$, and knowledge $(\mathrm{H} 2 \mathrm{e})$.

\section{Effects on Consultation Experience Outcomes: Question Asking and Anxiety}

The abovementioned effects of mode-tailored online information might also extend to the consultation and beyond (eg, patients' question asking and anxiety). Combining tailored preparatory information and interpersonal patient-provider communication can reinforce each other's effectiveness [31]. For instance, viewing preparatory information may make patients aware of topics of information they would like to know more about or validate with their health care provider, causing them to be more actively involved during consultations by asking questions $[30,32]$. Alternatively, patients viewing preparatory information before consultation may feel better informed and prepared for their visit, resulting in fewer questions asked during consultation [29]. Regardless, providing preparatory information in a tailored manner could strengthen effects in both directions (ie, more or less questions). As it is unclear how viewing mode-tailored online information before consultation would affect patients' question asking and how this differs by age, the following research questions were formulated:

\section{RQ1: Does exposure to a mode-tailored preparatory website (vs nontailored websites) lead to more or less questions asked by patients during consultation (T2)? \\ RQ2: To what extent does the relation between exposure to a mode-tailored preparatory website and patients' question asking during consultation differ between younger ( $<65$ years) and older patients $(\geq 65$ years)?}

Preparatory information can play a key role in limiting anxiety during cancer consultations, perhaps even more so for patients who tend to avoid information [24]. Bronner et al found that patients with cancer characterized by a monitoring coping style, that is, information seekers, became less anxious from pre- to postconsultation after receiving their diagnosis and treatment plan [24]. The opposite relation was found for patients identified more as information avoiders; this group became more anxious from pre- to postconsultation, especially when receiving bad news [24]. A possible explanation is that information seekers had already searched for information before their consultation and were prepared for the worst scenario. Thus, when hearing 
their diagnosis and treatment advice, they felt relieved when hearing relatively good news or they were more prepared for bad news. This is in contrast with the less prepared information avoiders who became more distressed after their consultation when receiving bad news. Therefore, we expect that the use of preparatory information before hospital visits, especially when tailored, decreases anxiety immediately after consultation.

- H3: Exposure to a mode-tailored preparatory website (vs nontailored websites) will decrease anxiety immediately after consultation (T2).

Additionally, we expect the effect of mode-tailored preparatory information on anxiety to be especially visible in older patients. The socioemotional selectivity theory posits that as people age, goals associated with emotional meaning and well-being become more salient, whereas knowledge-related goals to prepare for future events become less important [33]. Consequently, older adults generally process information in such a way that it helps them regulate their emotions (eg, putting them at ease). Older patients may perceive more emotional gratification from information presented in visual and audiovisual modes because these modes often include more vivid and obvious personal elements (eg, a patient video) that appeal more to their emotion-oriented preferences and needs. For instance, previous research has shown that older adults often prefer visual and audiovisual information [15,34], and such information modes have been found to increase feelings of emotional support from online cancer-related information compared with text in older people [35,36]. However, studies have also shown high variability in older adults' information mode preferences [12,37]. As such, providing older patients with the option to select their preferred information modes, including visual and audiovisual elements, is more likely to fulfil their emotional and informational needs, thereby limiting their anxiety.

- H4: The effect of mode tailoring on anxiety immediately after consultation will be stronger for older patients $(\geq 65$ years) than for younger patients ( $<65$ years).

\section{Effects on Knowledge and Recall of Information After the Consultation}

Consulting online information before consultations might also improve knowledge from online information and information recall after the consultation. For instance, when patients are already informed about several topics before consultations, this could prime patients' attention to these and related topics when being discussed by the provider during consultations (ie, a repetition effect) [38]. Additionally, being informed and knowing what to expect beforehand could leave patients with more cognitive capacity to attend to new information that they receive during consultations. In other words, providing information in a dosed manner over multiple occasions allows patients to process important information at a slower pace which may benefit information recall [39]. As older patients have more difficulty in remembering medical information, it is expected that they will benefit relatively more from mode-tailored preparatory information than younger patients.
- H5: Exposure to a mode-tailored preparatory website (vs nontailored websites) will improve knowledge from the website and information recall from the consultation (T3).

- H6: The effect on knowledge from the website and information recall from the consultation will be stronger for older patients ( $\geq 65$ years) than for younger patients $(<65$ years).

\section{Motivation- and Ability-Related Factors Explaining Patients' Information Processing}

Besides the main effects of mode tailoring on patient-reported outcomes before, during, and after the consultations, different website experience outcomes (eg, website involvement) may independently explain knowledge before the consultation (T1) and, together with consultation experience outcomes (T2; eg, question asking and anxiety), predict knowledge from the website and information recall from the consultation (T3). The different processes explaining knowledge acquisition and information recall can be related to a patient's motivation (eg, website involvement) or ability (eg, communication self-efficacy) to process information. Although ELM and LC4MP are useful frameworks in understanding how mode tailoring can enhance motivation and ability to process information, how these processes translate to specific variables explaining knowledge and recall of information in the cancer context has only been briefly explored $[5,6,40]$. For instance, Bol et al used ELM and LC4MP to identify motivation- and ability-related factors in the literature deemed relevant for processing of online cancer information [40]. They identified website involvement and website satisfaction as website experience outcomes positively associated with information recall, whereas perceived cognitive load was negatively related to information recall. However, Bol et al did not examine which consultation experience outcomes contribute to effective information processing in patient-provider encounters [40]. Thus, in addition to addressing the value of mode tailoring, this study sought to gain insight into which website experience outcomes and consultation experience outcomes explain the benefits of preparatory online information on knowledge acquisition from websites and information recall from consultations in patients with cancer, as well as how these concepts relate to each other over time. By doing so, we inform future research relying on theories such as the ELM and LC4MP to understand which specific motivation- and ability-related factors play a role in how online and offline cancer information is being processed. We explored the following research questions:

RQ3: Which website experience outcomes (eg, website use, website involvement, and anxiety) predict knowledge from the website before a consultation (T1)?

RQ4: Which website experience outcomes (T1) and which consultation experience outcomes (ie, question asking and anxiety; T2) predict knowledge from the website and information recall after the consultation (T3)? 


\section{Methods}

\section{Design}

An RCT was conducted to compare the effectiveness of a mode-tailored website (with options to choose text, visuals, and/or videos) with 3 standardized, nontailored versions with text only, text with visuals, and text with videos. Patients were stratified into a younger group ( $<65$ years $)$ and older group $(\geq 65$ years) and randomly assigned to view one of the 4 website versions. An age cut-off of 65 years was selected, as cancer more frequently occurs in adults above this age [1] and as similar studies on older patients and online health information also used this cut-off age [12,35,36]. An a priori power analysis based on an analysis of variance (ANOVA) with 8 groups (condition $\times$ age group) revealed that a sample size of 237 was needed to detect a medium-sized effect (Cohen $f=0.25$ ) with an observed power of 0.80 and an alpha level of .05 . The study was approved by the medical ethical review board of the Amsterdam University Medical Center (reference number: W13_053 \#13.17.0069) and the ethics committee of the Amsterdam School of Communication Research (reference number: 2014-CW-110).

\section{Participants}

Participants were patients who were suspected of having colorectal, stomach, or esophageal malignancies or had received a preliminary cancer diagnosis (but were awaiting information on the tumor stage based on additional imaging or came for a second opinion) who were referred to the Gastro-Intestinal Oncological Centre Amsterdam (GIOCA). Patients were recruited from December 2015 through September 2018. The GIOCA is an academic multidisciplinary outpatient clinic in the Netherlands that specializes in fast-track diagnosis and treatment planning within a day [41], referred to as the GIOCA day. During the study, 691 patients visited the GIOCA; of these, 643 were successfully approached by telephone 1 to 5 days before their visit, depending on the day they received their referral. We informed patients about the purpose of the study (ie, to gain insight into information provision to patients with cancer) and offered them access to a website containing relevant information about GIOCA's procedures, which could help them prepare for their visit. Of the 517 patients who had internet access and wanted to receive an email with access to the website, 241 consented to participate. As 9 of the included patients did not use the website, a total of 232 patients were included in the final analyses. Patients most often declined participation because they had no time or found it too burdensome. Only $8.0 \%$ $(22 / 276)$ of declining patients explicitly mentioned that recording their consultation was a breach of their privacy, and only $8.0 \%$ (22/276) had no interested in additional (online) information. A nonresponse analysis revealed no differences between participating and nonparticipating patients in age, $t_{689}=1.52 ; P=.13$, and gender, $\chi_{1}^{2}=3.2 ; P=.07$. An overview of participant inclusion, reasons for nonresponse, randomization procedure, and dropout rates is presented in Figure 1.

Figure 1. Flowchart of participant recruitment and drop-out.

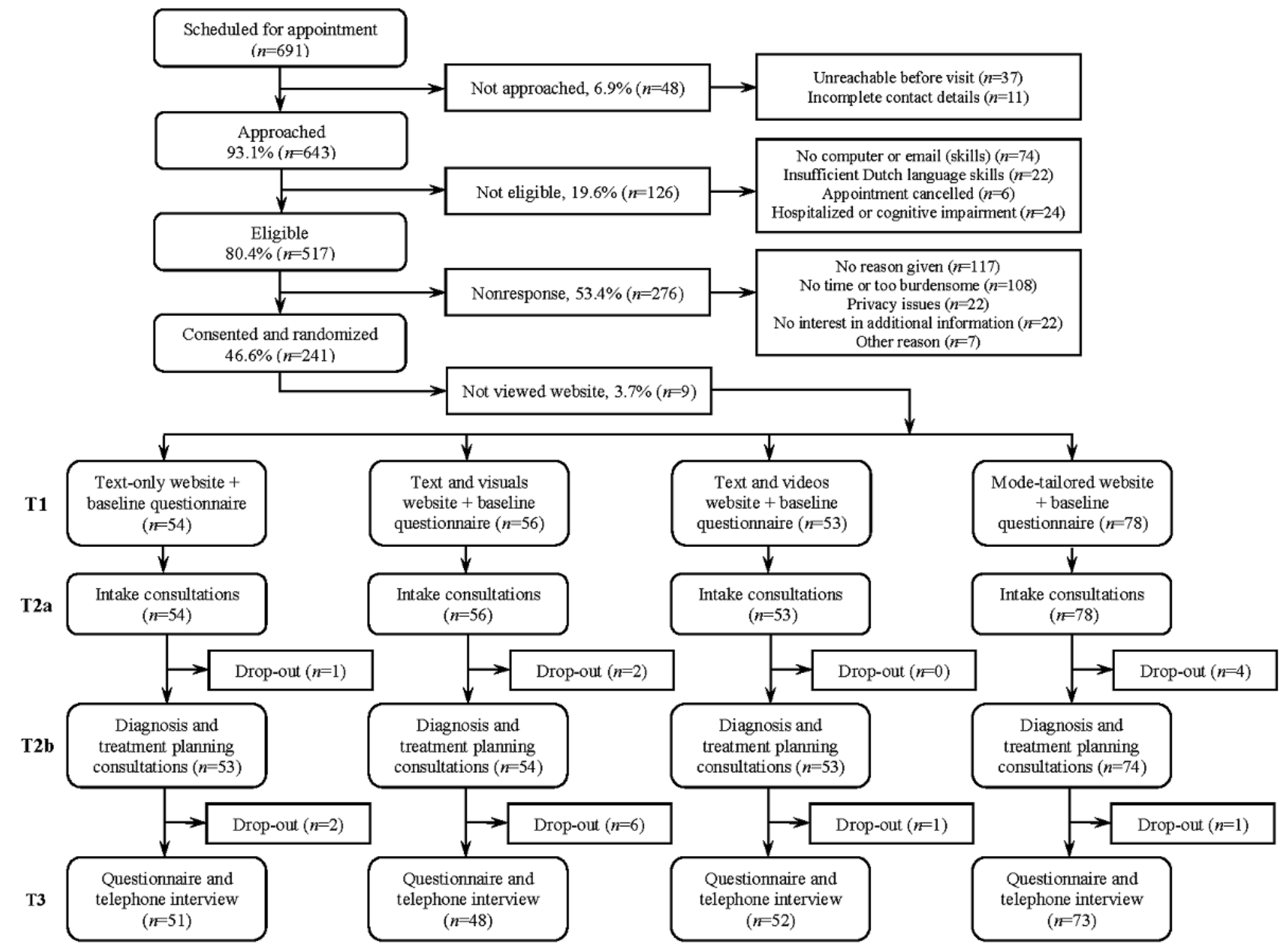




\section{Website Intervention}

A total of 4 website versions were developed containing the same information but presented in different modalities (via text, images, and/or patient videos). The nontailored website versions contained either text only, text with images, or text with videos. The text with videos version contained 6 videos featuring patients who narrated the textual information on the website (ranging from 1:30 to 3:00 min in length). As the images and videos were based on the textual content, they offered similar information. The information on the nontailored websites was offered in a standardized manner and could not be adapted by patients. The mode-tailored website version allowed patients to self-tailor the information presentation to their preferred mode at any moment during viewing. We did not include a nontailored version with all modalities, as we previously found that too much information on one Webpage can be detrimental for patient outcomes [18].

The website contained different pages with information about the fast-track clinic, how to prepare for consultations, and when to contact the clinic. Furthermore, the website contained information about the conditions (colorectal, stomach, or esophageal cancer), medical tests, treatment options, and practical information, such as a list of health care providers, frequently asked questions, and contact and location information. The content on the websites was similar for both patients with colorectal cancer and patients with stomach and esophageal cancer, except for the information concerning the condition and treatment options. Details on the development and content of these websites are published elsewhere [27]. Examples of the mode-tailored website and the nontailored websites are given in Figures 2 and 3.

Figure 2. Example of the mode-tailored website with all modes switched on (text, images, videos).

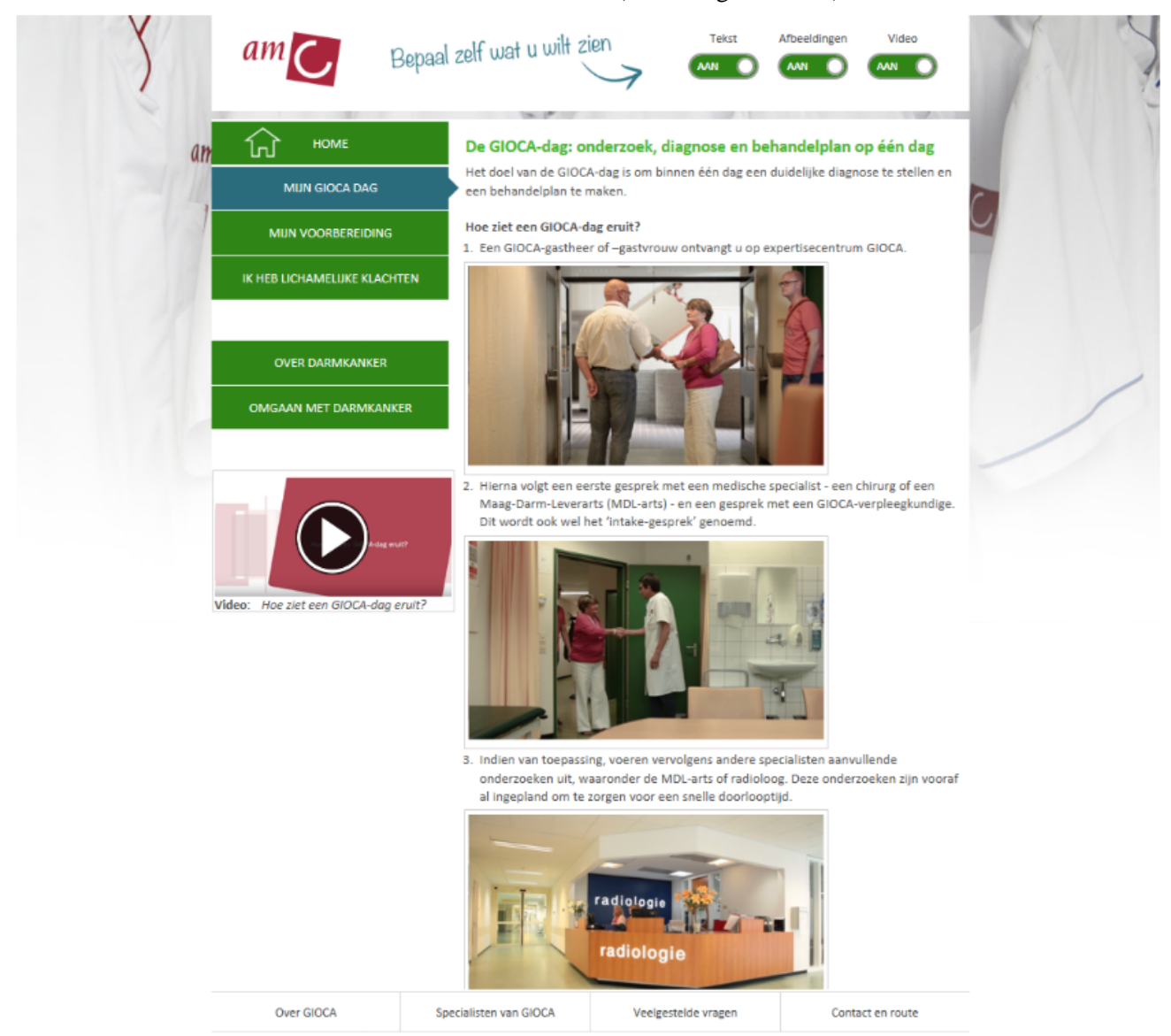


Figure 3. Example of a non-tailored website with text and video.

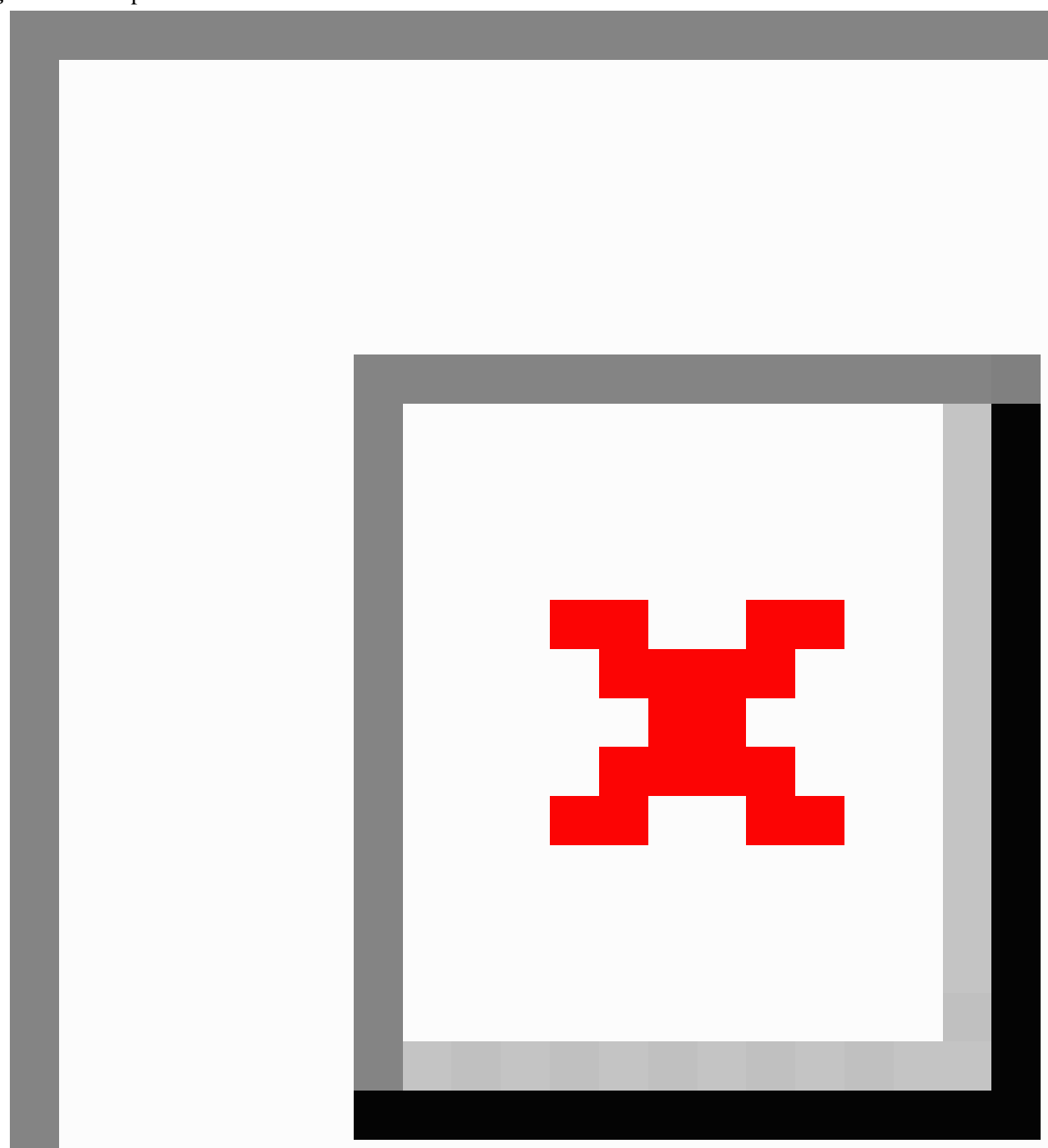

\section{Procedure}

Consenting patients were stratified by age group and then randomized to one of the 4 conditions using randomization software. After the first telephone contact (1-5 days before visit), patients received a link to one of the 4 website versions by email from the study coordinator. Patients were not aware that there were other website versions than the one they received. Patients were free to use the website as they wished (how often, how long, and which pages). After viewing the website, consenting patients completed an online questionnaire to record website experience outcomes and background variables such as sociodemographic information, health background information, and information preference characteristics (T1a). One day before their visit to the clinic, patients' knowledge acquired from the website was assessed by telephone (T1b). On the day of the patients' visit to the clinic, a research assistant was present in the hospital to video record all consultations to assess question asking during consultations (T2). The fast-track program (GIOCA day) started with 2 intake consultations (medical specialist and nurse) to evaluate symptoms and medical history (T2). At noon, a multidisciplinary team discussed the diagnosis and formulated a treatment plan. In the afternoon, the diagnosis and treatment advice were discussed with the patient by the physician and nurse who conducted the intake consultations (T2). Depending on the treatment plan, patients also visited a surgeon, oncologist, or radiation oncologist on the same day to discuss treatment details (T2). Patients usually had 4 to 7 
consultations during the GIOCA day, all of which were video recorded for this study. Immediately after the last consultation, a paper questionnaire was used to measure anxiety (T2). Patients were contacted by telephone within 36 to 48 hours after their visit to assess their knowledge from the website and information recall from the consultation (T3).

We took extensive measures to limit the overall participant burden. We had a trained research assistant who informed patients at the start of the study by telephone to ensure they knew exactly what the participation would entail, including how their privacy was safeguarded. Then, we sent out an information letter over email and contacted patients after 2 days again. Every patient was in contact with 1 research assistant who conducted telephone interviews before and after consultation and accompanied the patient in the hospital for data collection (handing out the questionnaires at the right time and installing the video recorder). This ensured that both patients and providers dealt with 1 person only and did not have to memorize when to fill out which questionnaire or turn on the video recording.

\section{Perceived Level of Tailoring of the Website}

We measured to what extent patients felt the website was tailored to their situation with 2 items. The items comprised "the way I viewed information on the website (via text; text with images; text with video; text, images, and/or video) corresponded to my preference to receive health information" and "the presentation of the information on the GIOCA website was tailor-made for me." The answer options ranged from 1 (totally disagree) to 7 (totally agree), with higher scores indicating higher levels of perceived tailoring (Pearson $r=0.74$; $P<.001)$.

\section{Website Experience Outcomes (T1)}

Website use patterns were recorded using a built-in Web tracker that logged every action on the website, including the number of clicks, time spent on each page, video viewing behavior, mode selections, and number of visits.

Website involvement was measured with 5 items, including "I was highly involved in evaluating the website" and "I carefully viewed the information on the website" [42]. Answer options ranged from 1 (totally disagree) to 7 (totally agree), of which mean scores were calculated (alpha $=.81$ ).

The 10-item version of the Website Satisfaction Scale [18,43] was used to assess the degree to which patients were satisfied with the (1) attractiveness of the website (3 items, eg, the website looks nice; alpha=.86), (2) comprehensibility of the website (3 items, eg, "the website is understandable"; alpha=.97), and emotional support from the website (4 items, eg "the website helps me with my emotions"; alpha=.92). Answer options ranged from 1 (totally disagree) to 7 (totally agree), of which mean scores were calculated.

Communication self-efficacy was measured with the short-form Perceived Efficacy in Patient-Physician Interactions questionnaire [44]. A total of 5 questions assessed the patient's confidence in their ability to communicate with their provider on a scale from 1 (very confident) to 5 (not confident at all). A sum score was calculated (range 5-25; alpha=.88).
Patients' current state of anxiety was measured with the 6-item version of the State-Trait Anxiety Inventory (STAI-6) [45]. Patients rated whether they experienced the presence (tense, upset, or worried) or absence (calm, relaxed, or content) of anxiety from 1 (not at all) to 4 (very much so). On the basis of the guidelines, the scores were recoded to range from 20 to 80 , with scores $>44$ indicating high anxiety (alpha $=.80)$ [46].

Knowledge acquired from the website was measured using the protocol of the Netherlands Patient Information Recall Questionnaire (NPIRQ) via telephone interviews [6,47]. We asked patients 12 standardized open questions based on the website content (eg, about the goal and course of the fast-track program and which medical specialists they will see). On the basis of a predeveloped code book, for 9 questions, patients could score 2 points, and for 3 questions, the correct answers contained fewer or more elements, and thus, these questions accounted for $1,2.5$, and 3 points. Thus, the maximum knowledge score at $\mathrm{T} 1$ for 12 questions $(9 \times 2+1 \times 1+1 \times 2.5+$ $1 \times 3$ ) was 24.5 . A standardized score was calculated by taking the percentage correctly answered according to the NPIRQ guidelines. The first author (MHN) coded all the answers. Additionally, answers from 14 patients were double coded by a second coder (FY), showing good intercoder reliability (mean kappa $=0.737 ; P=<.001)$.

\section{Consultation Experience Outcomes (T2)}

Anxiety immediately after consultation was measured in the same way as before the consultation (STAI-6; mean 41.45, SD 11.76; Cronbach alpha=.81).

To code the question-asking behavior, a codebook was developed based on earlier work by Zandbelt et al [48]. All questions during consultation related to (1) medical, (2) practical, and (3) paramedical information were coded. Questions on medical topics were about the patients' disease, treatment (options), complications, and side effects. Questions on practical topics were about logistics of treatment and follow-up appointments. Questions on paramedical information were about psychosocial topics and consequences for daily life. Questions that were unrelated to the patient's condition (eg, the weather and holiday) were not coded. All questions were summed into one total score. A total of 16 consultations were double coded, revealing good intercoder reliability (Krippendorff alpha=.951).

\section{Recall of Information and Knowledge After the Consultation (T3)}

Information recall from the consultation and knowledge from the website were measured with the NPIRQ (similar to measurement of knowledge before the consultation; T1). Regarding information recall from the consultation, each participant was asked 13 standardized open questions (eg, about the proposed treatment plan, logistic planning of treatment, possible risks and side effects of treatment, and recommendations for daily life). To improve the validity of the recall measure, a maximum of 5 additional open questions were formulated, tailored to each patient's videotaped consultations (eg, about details of treatment and additional medical tests). The correct answers were derived from the videotaped 
consultations. Each answer as provided by the participant during the interview was scored as not recalled (0), partially recalled (1), and completely recalled (2) based on a predeveloped code book. In theory, patients could receive a maximum of 18 questions (13 standardized +5 tailored questions). However, as the content of consultations varied between patients, not all standardized open questions were applicable to all patients. Similar to T1, a standardized score was calculated by taking the percentage of correctly recalled information, based on the patient's total sum score (1-23) and the maximum obtainable recall score (range 4-34; mean 56.37, SD 15.21).

The website contained information on 10 of the 13 standardized open questions asked. Hence, a separate knowledge score about topics on the website was calculated from these 10 questions. For this knowledge score, the website content was used as a guideline to score patients' answers (similar to knowledge at T1). Again, a standardized score was calculated by taking the percentage correctly answered, based on the total sum score (0-9) and maximum obtainable score (range 10-19; mean 15.05, $S D$ 11.76). The first author (MHN) coded all answers. A second coder (MA) coded answers from 14 participants from a different dataset with the exact same code book (mean kappa $=0.816$; $P<.001)$ [6].

\section{Background Variables}

\section{Sociodemographic Information}

Sociodemographic information included age, gender, and education level. Education level was divided into lower (ie, primary education, general secondary education, and middle vocational education) and higher education level (ie, higher vocational education and university).

\section{Health Background Information}

Health background information included cancer type (coded as colorectal cancer $=0$ and esophageal/stomach cancer=1) and whether patients came in for a second opinion (no=0 and yes $=1$ ). The treatment goal (palliative or unclear $=0$ and curative $=1$ ) was derived from the medical file. Health literacy was measured with the comprehension test of the Short Assessment of Health Literacy in Dutch that consists of 22 health-related words (eg, biopsy, ventricle, and palliative) [49]. For each word, people were asked to select the correct meaning out of 3 multiple choice options or an "I don't know" option. The sum score of correct answers reflects their health literacy level and could range between 0 and 22. Patients' frailty (ie, functioning in the physical, cognitive, social, and psychosocial domain) was assessed with the 15-item Groningen Frailty Indicator [50]. The quality of life was measured with 2 items from the European Organisation for Research and Treatment of Cancer Quality of Life Questionnaire [51] with answer options ranging from 1 (very bad) to 7 (excellent; Pearson $r=0.75 ; P<.001$ ).

\section{Information-Seeking Characteristics}

Internet use was measured in hours per week. Monitoring coping style refers to the degree to which patients seek information in a threatening medical situation. This was assessed with an adapted version of the Threatening Medical Situation Inventory (eg, "I intend to get as much information as possible about my treatment") [24,52], using 3 items with answer options from 1 (not applicable to me at all) to 5 (very applicable to me; Cronbach alpha=.83). We assessed information preference with an adapted item from the Information Satisfaction Questionnaire [53], asking whether patients prefer to receive (1) "as much information as possible, both positive and negative," (2) "as much information as possible, both positive and negative, but bit by bit," (3) "not much information," and (4) "only positive information". In conformity with previous research [54], the items were dichotomized by merging category (2), (3), and (4) into "not all information (at once)" (0) versus "as much information as possible, both positive and negative" (1). Finally, we assessed whether patients received information about the clinic from other sources (eg, health care providers and brochures) besides our website (no=0 and yes $=1$ ).

\section{Statistical Analyses}

Chi-square tests, $t$ tests, and ANOVAs were conducted to check for unequal distribution of background variables over conditions. Descriptive analyses were used to explore patterns of website use. Main and interaction effects of mode tailoring (H1-H6, RQ1-2) were tested with ANOVAs. Additional simple effects analyses were conducted to examine differences between conditions within age groups. The significance level was set at $P<.05$. To test which website experience outcomes predicted knowledge before the consultation (T1) and how these, together with consultation experience outcomes (T2), predicted information recall from the consultation and knowledge from the website after the consultation (T3; RQ3-4), 3 multistage linear regression models were estimated. All analyses started with a baseline model (Model 1) of individual background variables (with age as a continuous variable). Website experience outcomes were added as predictors in Model 2. For information recall from the consultation and knowledge from the website at T3, relevant consultation experience outcomes (T2) were included as predictors in Model 3. To reduce the number of predictors, only variables that were at least marginally correlated with knowledge or information recall were included in the models $(P<.10)$. Assumptions of linearity, normality, homoscedasticity, independent errors (Durbin-Watson values for Model 1, 2, and 3 are 1.95, 1.89, and 1.75, respectively) and multicollinearity (variance inflation factor $<10$ ) were met for all variables. Standardized coefficients (betas) are reported for comparisons of predictive power.

\section{Results}

\section{Patient Characteristics}

Participating patients were aged, on average, 63.50 years (SD 9.06; range $36-86)$, with $46.1 \%$ (107/232) aged $\geq 65$ years. The majority were male $(68.1 \%, 158 / 232)$ and lived together with their spouse, children, or other family members $(82.8 \%$, 192/232). The majority were advised a curative treatment plan $(73.2 \%, 170 / 232)$, whereas $13.4 \%(31 / 232)$ entered a palliative trajectory, and $13.4 \%$ (31/232) were scheduled for additional imaging studies to formulate a clear diagnosis and treatment plan. Of the 232 participating patients, 74 viewed the mode-tailored website, 53 viewed the text-only website, 54 viewed the text with images website, and 51 viewed the text 
with video website. Background information of the patients is given in Table 1.

Table 1. Patient background characteristics.

\begin{tabular}{|c|c|c|c|c|}
\hline Background variables $^{\mathrm{a}}$ & Older patients $(\mathrm{n}=107)$ & Younger patients $(n=125)$ & All patients $(n=232)$ & $\operatorname{Total}(\mathrm{N})^{\mathrm{b}}$ \\
\hline \multicolumn{5}{|l|}{ Sociodemographic information } \\
\hline Age (years), mean (SD) & $71.44(4.23)$ & $56.81(6.18)$ & $63.50(9.06)$ & 232 \\
\hline \multicolumn{5}{|l|}{ Gender } \\
\hline Male, $\mathrm{n}(\%)$ & $77(72.6)$ & $81(64.3)$ & $158(68.1)$ & 232 \\
\hline Female, n (\%) & $29(27.4)$ & $45(35.7)$ & $74(31.9)$ & 232 \\
\hline \multicolumn{5}{|l|}{ Education level } \\
\hline Lower, n (\%) & $71(67.0)$ & $75(59.5)$ & $146(62.9)$ & 231 \\
\hline Higher, n (\%) & $35(33.0)$ & $50(39.7)$ & $85(37.1)$ & 231 \\
\hline \multicolumn{5}{|l|}{ Health background information } \\
\hline \multicolumn{5}{|l|}{ Cancer type $^{\mathrm{c}}$} \\
\hline Colorectal, n (\%) & $77(72.6)$ & $110(87.3)$ & $187(77.9)$ & 232 \\
\hline Esophageal/stomach, n (\%) & $29(27.4)$ & $16(12.7)$ & $45(22.1)$ & 232 \\
\hline \multicolumn{5}{|l|}{ Second opinion } \\
\hline No, n (\%) & $90(84.9)$ & $99(78.6)$ & $189(81.5)$ & 232 \\
\hline Yes, n (\%) & $16(15.1)$ & $27(21.4)$ & $43(18.5)$ & 232 \\
\hline \multicolumn{5}{|l|}{ Treatment goal } \\
\hline Palliative, n (\%) & $13(12.3)$ & $18(14.3)$ & $31(13.4)$ & 232 \\
\hline Curative, n (\%) & $81(76.4)$ & $89(70.6)$ & $170(73.2)$ & 232 \\
\hline Unclear, n (\%) & $12(11.3)$ & $19(15.1)$ & $31(13.4)$ & 232 \\
\hline Health literacy ${ }^{\mathrm{d}}$, mean (SD) & $16.50(4.99)$ & $16.82(4.38)$ & $16.66(4.66)$ & 182 \\
\hline Frailty $^{\mathrm{e}}$, mean (SD) & $2.19(1.86)$ & $2.69(2.05)$ & $2.46(1.98)$ & 182 \\
\hline Quality of life ${ }^{\mathrm{f}}$, mean (SD) & $5.24(1.17)$ & $4.99(1.36)$ & $5.11(1.28)$ & 229 \\
\hline \multicolumn{5}{|l|}{ Information characteristics } \\
\hline Internet useb ${ }^{\mathrm{b}, \mathrm{g}}$, mean $(\mathrm{SD})$ & $12.02(10.30)$ & $17.98(17.74)$ & $15.27(15.10)$ & 229 \\
\hline Information coping style ${ }^{\mathrm{h}}$, mean (SD) & $3.74(0.87)$ & $3.76(0.87)$ & $3.75(0.87)$ & 229 \\
\hline \multicolumn{5}{|l|}{ Information preference } \\
\hline Not all information, $\mathrm{n}(\%)$ & $25(24.0)$ & $31(24.8)$ & $56(24.5)$ & 229 \\
\hline As much information as possible, $\mathrm{n}(\%)$ & $79(76.0)$ & $94(75.2)$ & $173(75.5)$ & 229 \\
\hline \multicolumn{5}{|l|}{ Additional information received } \\
\hline No, n (\%) & $30(30.9)$ & $38(31.4)$ & $68(31.2)$ & 218 \\
\hline Yes, n $(\%)$ & $67(69.1)$ & 83 (68.6) & $150(68.8)$ & 218 \\
\hline
\end{tabular}

${ }^{\mathrm{a}}$ No differences were found between conditions.

${ }^{\mathrm{b}} N$ refers to the entire population under study and $n$ refers to a sample population under study. Not all cells add up to $100 \%$ owing to missing data.

${ }^{\mathrm{c}}$ Differs significantly between younger and older patients at $P<.01$.

${ }^{\mathrm{d}}$ A higher score indicates higher levels of health literacy (maximum range: 0-22; reported range 0-22).

${ }^{\mathrm{e}} \mathrm{A}$ higher score indicates higher frailty (maximum range 1-15; reported range 0-10).

${ }^{\mathrm{f}}$ A higher score indicates higher quality of life (maximum range 1-7; reported range 2-7).

${ }^{\mathrm{g}}$ Measured in hours per week.

${ }^{\mathrm{h}} \mathrm{A}$ higher score indicates a higher information monitoring coping style (maximum range 1-5; reported range 1-5). 


\section{Perceived Level of Tailoring}

Patients viewing the mode-tailored website version had equally high perceptions of the degree to which the information presentation was tailored to them as compared with those viewing the nontailored versions (mean 5.24, SD 1.22; $\left.F_{3,225}=0.19 ; P=.91 ; \eta \mathrm{p}^{2}=0.00\right)$.

\section{Website Use Patterns}

Of the 232 participating patients, 74 viewed the mode-tailored website (31.9\%), 53 viewed the text-only website (22.8\%), 54 viewed the text with images website $(23.3 \%)$, and 51 viewed the text with video website $(23.0 \%)$. Patients spent an average of $34 \mathrm{~min}$ and 45 seconds on the website ( $S D$ 00:32:56; range 00:00:34-03:50:42). Patients who received the website a day before their visit did not spend less time on the website than those who received it earlier $\left(t_{230}=1.79 ; P=.07\right)$ and this did not differ between conditions $\left(\chi_{3}^{2}=1.1 ; P=.76\right)$. The majority of patients $(62.1 \%, 144 / 232)$ visited the website twice or more in the days before their visit (mean 2.78, SD 2.28; range 1-22). Patients mostly consulted information about the GIOCA day $(90.9 \%, 211 / 232)$, how to prepare for their visit $(86.6 \%$, 201/232), their condition (colorectal, stomach, or esophageal cancer; $80.6 \%, 187 / 232$ ), and how to deal with cancer in daily life (ie, nutrition, fatigue, and psychosocial care; $67.2 \%$, $156 / 232$ ), and with which symptoms to contact the hospital $(65.1 \%, 151 / 232)$. Almost half of the patients viewed information on diagnostic tests $(40.5 \%, 94 / 232)$ and frequently asked questions $(48.3 \%, 112 / 232)$. Contact information (27.2\%, $63 / 232$ ), information about which medical specialists work at GIOCA $(19.8 \%, 46 / 232)$, and information on additional websites $(25.0 \%, 58 / 232)$ were least often consulted. An overview of website use patterns is presented in Table 2.

Videos were available for patients in the text with video condition and mode-tailored condition (total $n=125$ ). Of these patients, $41\left(32.8 \% ; n_{\text {tailored }}=18 ; n_{\text {video }}=23\right)$ watched a total of 96 videos on the website. Within the conditions, $28 \%(21 / 74)$ of patients in the tailored condition watched a video compared with $39 \%(20 / 51)$ in the text with video condition. Within age groups, $29 \%$ (16/54) of older patients watched a video compared with $35 \%(25 / 71)$ of younger patients. These differences were not significant. Most patients who watched a video, watched it almost completely (total video time: mean 00:06:52, SD 00:05:19, range 00:15-22:35). The majority of patients who watched videos, watched more than one $(61 \% ; 25 / 41)$.

Patients in the mode-tailored condition spent an average of 43:07 min on the website, compared with 30:59 min for patients in the text condition, 33:52 min for patients in the text with images condition, and 26:26 min for patients in the text with video condition. However, this difference was not significant $\left(F_{3,224}=2.52 ; P=.06 ; \eta p^{2}=0.03\right)$. There were no differences between age groups in terms of time spent on the website $\left(F_{3,224}=0.00 ; P=.96 ; \eta \mathrm{p}^{2}=0.00\right)$. All patients in the mode-tailored condition chose at least text, but the majority supplemented this with additional images or videos spread over multiple visits to the website. The majority of patients $(77 \%, 57 / 74)$ in the mode-tailored condition selected all 3 modalities (text, images, and video); $16 \%$ of patients (12/74) chose text and images; $1 \%$ of patients (4/74) chose text only; and only 1/74 patient chose text with video. Regarding the first time on the website, most patients first chose text $(79 \%, 59 / 74) ; 13 \%$ of patients first chose images (10/74); and $6 \%$ of patients first chose video (5/74). During subsequent Web sessions, patients were more likely to choose images and video first. On average, patients took 01:15 min to select their first mode (SD 02:10; 39\%, 29/74<30 seconds, 66\%, 50/74<1 $\mathrm{min}$, and $86.5 \%, 64 / 74<2 \mathrm{~min}$ ). Regarding the second visit, the first mode was selected on average at 29 seconds ( $S D$ 00:51; 84\%, 32/38<30 seconds, $94.7 \%, 36 / 38<2 \mathrm{~min})$. 
Table 2. Patterns of website use.

\begin{tabular}{|c|c|c|c|}
\hline Website use variables & Older patients $(\mathrm{n}=106)$ & Younger patients $(\mathrm{n}=126)$ & All patients $(n=232)$ \\
\hline Time spent on website (mm:ss), mean (SD) & $34: 27(32: 09)$ & $35: 00(33: 42)$ & $34: 45(32: 56)$ \\
\hline Mode-tailored $(31.9 \%, \mathrm{n}=74)$ & $41: 35(40: 55)$ & $44: 14(43: 01)$ & 43:07 (41:53) \\
\hline Text-only $(22.8 \%, \mathrm{n}=53)$ & $30: 25(39: 34)$ & $31: 31(22: 11)$ & $30: 59(25: 49)$ \\
\hline Text with images $(23.3 \%, \mathrm{n}=54)$ & $34: 09(30: 34)$ & $33: 35(35: 23)$ & $33: 52(32: 51)$ \\
\hline Text with video $(23.0 \%, \mathrm{n}=51)$ & $29: 42(21: 55)$ & $25: 33(20: 15)$ & $26: 26(20: 55)$ \\
\hline \multicolumn{4}{|l|}{ Web pages, n (\%) } \\
\hline The GIOCA ${ }^{\mathrm{a}}$-day & $90(84.9)$ & $121(96)$ & $211(90.9)$ \\
\hline Preparing for the GIOCA-day & $84(79.2)$ & $117(92.9)$ & $201(86.6)$ \\
\hline Information about cancer types & $84(79.2)$ & $103(81.7)$ & $187(80.6)$ \\
\hline Diagnostic tests & $49(46.2)$ & $45(35.7)$ & $94(40.5)$ \\
\hline When to contact the hospital & $62(58.5)$ & 89 (70.6) & $151(65.1)$ \\
\hline Daily life recommendations & $65(61.3)$ & $91(72.2)$ & $156(67.2)$ \\
\hline Additional relevant websites & $23(21.7)$ & $35(27.8)$ & $58(25.0)$ \\
\hline Frequently asked questions & $48(45.3)$ & $64(50.8)$ & $112(48.3)$ \\
\hline Medical specialists at GIOCA & $23(21.7)$ & $23(18.3)$ & $46(19.8)$ \\
\hline Contact information & $31(29.2)$ & $32(25.4)$ & $63(27.2)$ \\
\hline Watched at least one video $^{b}, \mathbf{n}(\%)$ & $16(29.6)$ & $25(35.2)$ & $41(32.8)$ \\
\hline Mode-tailored & $9(29.0)$ & $12(27.9)$ & $21(28.4)$ \\
\hline Text with video & $7(30.4)$ & $13(46.4)$ & $20(39.2)$ \\
\hline Number of videos watched ${ }^{\mathrm{c}}, \mathrm{n}(\%)$ & $2.50^{\mathrm{d}}(2.50)$ & $2.24^{\mathrm{e}}(1.30)$ & $2.34^{\mathrm{d}}(1.84)$ \\
\hline Mode-tailored & $3.00^{\mathrm{d}}(3.28)$ & $2.50^{\mathrm{e}}(1.57)$ & $2.71^{\mathrm{d}}(2.39)$ \\
\hline Text with video & $1.86^{\mathrm{f}}(0.69)$ & $2.00^{\mathrm{g}}(1.00)$ & $1.95^{\mathrm{g}}(0.89)$ \\
\hline Number of mode actions ${ }^{\mathrm{h}}$, mean (SD) & $2.97(7.27)$ & $2.72(6.26)$ & $2.84(6.72)$ \\
\hline Time until first mode $(\mathrm{mm}: \mathrm{ss})^{\mathrm{h}}$, mean (SD) & 01:00 (00:48) & $01: 25(02: 45)$ & $01: 15(02: 10)$ \\
\hline First mode $\leq 1 \min (\%)$ & 64.5 & 67.4 & 66.2 \\
\hline First mode $\leq 2 \min (\%)$ & 87.1 & 86 & 86.5 \\
\hline First mode $\leq 4 \min (\%)$ & 100 & 95.3 & 97.3 \\
\hline \multicolumn{4}{|l|}{ First mode chosen ${ }^{b, h}, \mathbf{n}(\%)$} \\
\hline Text & $27(87.1)$ & $32(74.4)$ & $59(79.7)$ \\
\hline Illustrations & $4(12.9)$ & $6(14.0)$ & $10(13.5)$ \\
\hline Video & $0(0.0)$ & $5(11.6)$ & $5(6.8)$ \\
\hline \multicolumn{4}{|l|}{ Mode combinations ${ }^{b, h}, \mathbf{n}(\%)$} \\
\hline All 3 modes & $23(74.2)$ & $34(79.1)$ & $57(77.0)$ \\
\hline Text and illustrations & $8(25.8)$ & $4(9.3)$ & $12(16.2)$ \\
\hline Text and video & $0(0.0)$ & $1(2.3)$ & $1(1.4)$ \\
\hline Text only & $0(0.0)$ & $4(9.3)$ & $4(5.4)$ \\
\hline
\end{tabular}

${ }^{a}$ GIOCA: Gastro-Intestinal Oncological Centre Amsterdam

${ }^{\mathrm{b}}$ Only applicable to patients viewing the mode-tailored $(\mathrm{n}=74)$ and text with video website $(\mathrm{n}=51)$.

${ }^{\mathrm{c} O n l y}$ includes patients who watched at least one video.

${ }^{\mathrm{d}}$ Range: 1-11.

${ }^{\mathrm{e}}$ Range: 1-6. 
${ }^{f}$ Range: 1-3.

${ }^{g}$ Range: 1-4.

${ }^{\mathrm{h}}$ Only applicable to patients viewing the mode-tailored website $(\mathrm{n}=74)$.

\section{Effects on Website Experience Outcomes Before Consultation (T1)}

Table 3 shows the summary statistics of all outcomes. We hypothesized that exposure to a mode-tailored website (vs nontailored websites) would positively affect patients' website involvement, website satisfaction, anxiety, communication self-efficacy, and knowledge before the consultation (H1). Our data showed no significant differences between the conditions for these website experience outcomes. We also hypothesized differential effects of mode tailoring for younger and older patients, with stronger effects for older patients (H2). Although no significant interaction effects were present, a simple effects analysis revealed that, in contrast with our hypothesis, for younger patients the mode-tailored website (mean 5.12, SD $0.97 ; P=.02$ ) and text with images website (mean 5.30, SD 0.91; $P=.009)$ resulted in higher satisfaction with the attractiveness of the website compared with the text-only website (mean 4.46, $S D$ 1.08). In general, older patients had lower knowledge levels (mean 22.70, SD 12.57) than younger patients (mean 30.16, SD $\left.13.00 ; F_{3,218}=17.91 ; P<.001 ; \eta p^{2}=0.08\right)$. Overall, the data showed no support for $\mathrm{H} 1$ and $\mathrm{H} 2$.

Table 3. Means and standard deviations of patient outcome variables.

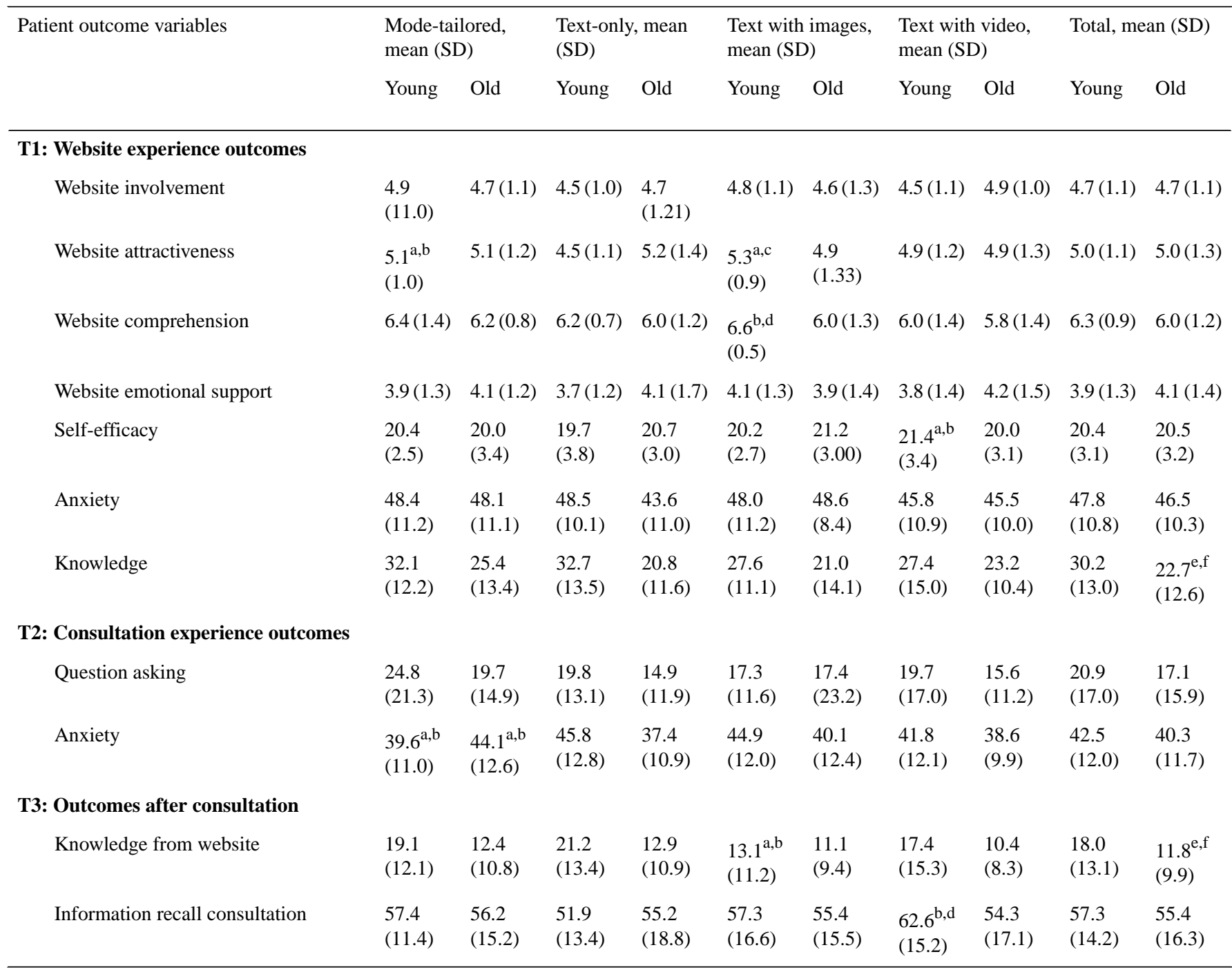

${ }^{\mathrm{a}}$ Differs from text-only condition.

${ }^{\mathrm{b}}$ Significant at $P<.05$.

c Significant at $P<.10$.

${ }^{\mathrm{d}}$ Differs from text with video condition.

${ }^{\mathrm{e}}$ Differs from younger patients.

${ }^{\mathrm{f}}$ Significant at $P<.001$. 


\section{Effects on Consultation Experience Outcomes (T2)}

We explored whether exposure to a mode-tailored website would influence the number of questions asked by patients during consultations (RQ1) and whether this would differ between younger and older patients (RQ2). Results showed no significant differences between condition and no interaction effects between condition and age for the number of questions asked during consultations. Additionally, we hypothesized that exposure to a mode-tailored website (vs nontailored websites) would decrease anxiety immediately after consultation (H3), with stronger effects for older patients (H4). Although we found no main effect of condition, a significant interaction between condition and age group was revealed $\left(F_{3,204}=3.16 ; P=.03\right.$; $\left.\eta \mathrm{p}^{2}=0.04\right)$. However, in contrast with our expectations, older patients reported higher anxiety in the mode-tailored condition (mean 44.14, SD 12.62; $P=.04$ ) compared with the text condition (mean 37.36, SD 10.86). On the contrary, younger patients reported lower levels of anxiety in the mode-tailored condition (mean 39.59, SD 10.97; $P=.046$ ) compared with the text condition (mean 45.80, SD 12.80). Overall, the data showed no support for $\mathrm{H} 3$ and contrasting results for $\mathrm{H} 4$.

\section{Effects on Information Recall and Knowledge After Consultation (T3)}

We hypothesized that exposure to a mode-tailored (vs nontailored) website would increase patients' knowledge from the website and information recall from the consultation (H5), with differential effects for younger and older patients (H6). For both outcomes, we found no significant differences between conditions and no interaction effects. Overall, older patients acquired less knowledge from the website (mean 11.78, SD 9.88) than younger patients (mean 17.96, $S D$ 13.12; $\left.F_{1,194}=12.89 ; P<.001 ; \eta \mathrm{p}^{2}=0.06\right)$. There were no age differences in recall from the consultation (mean younger $=57.29, S D$ 14.15; mean $_{\text {older }}=55.35, S D$ 16.33).

\section{What Motivation- and Ability-Related Factors Explain Knowledge and Information Recall Before and After Consultation?}

Table 4 summarizes all regression models. Regarding knowledge from the website before the consultation (T1), the baseline model with individual background variables (Model 1; $\mathrm{n}=211$ ) revealed that younger age (beta=-.23; $P=.001$ ) and higher education levels (beta $=.22 ; P=.002$ ) were associated with higher knowledge. Patients who received information about the clinic from other sources also reported higher knowledge (beta=.13; $P=.06$ ); however, this effect was not significant. Extending this model with website experience outcomes (Model 2) significantly improved the model $\left(\Delta R^{2}=0.06 ; P=.006\right.$; total adjusted $\left.R^{2}=0.17\right)$. Higher perceived website involvement (beta=.15, $P=.03$ ) and higher satisfaction with the comprehensibility of the website (beta=.15, $P=.05$ ), although the latter borderline significant, are associated with higher knowledge at $\mathrm{T} 1$.

Regarding information recall from the consultation (T3), no background variables were associated with information recall (Model 1, n=194). Extending the model with website experience outcomes revealed that knowledge before the consultation (beta=.22; $P=.003$ ), whether the patient had watched a video on the website (beta=.14; $P=.07$ ), and communication self-efficacy (beta=.12;P=.09) explained a significant additional proportion of variance in information recall $\left(\Delta R^{2}=0.12 ; P=.001\right.$; total adjusted $\left.R^{2}=0.09\right)$. The latter 2 variables were however not significantly related to information recall. No consultation experience outcomes were associated with information recall from the consultation at $\mathrm{T} 3$.

Regarding knowledge from the website after the consultation (T3), the baseline model with control variables (Model 1, $\mathrm{n}=185$ ) revealed that younger age (beta $=-18 ; P=.02$ ) and higher education levels (beta $=.16 ; P=.03$ ) were associated with higher knowledge. Extending this model with website experience outcomes significantly improved the model $\left(\Delta R^{2}=0.19 ; P<.001\right.$; total adjusted $R^{2}=0.27$ ). Specifically, more time spent on the website before the consultation (beta $=.21 ; P=.002$ ) and higher knowledge at $\mathrm{T} 1$ (beta $=.39 ; P<.001)$ were associated with higher knowledge at T3. Age (beta $=-.08 ; P=.23$ ) and education level (beta=.10; $P=.12$ ) became insignificant predictors of knowledge. No consultation experience outcomes were associated with knowledge at T3. 
Table 4. Regression models predicting knowledge and information recall.

\begin{tabular}{|c|c|c|c|c|c|c|c|c|c|c|c|c|c|c|}
\hline \multirow[t]{3}{*}{ Regression outcomes $^{\mathrm{a}}$} & \multicolumn{4}{|c|}{ Website knowledge $(\mathrm{T} 1 ; \mathrm{n}=211)^{\mathrm{b}}$} & \multicolumn{4}{|c|}{$\begin{array}{l}\text { Information recall consultation } \\
(\mathrm{T} 3 ; \mathrm{n}=194)^{\mathrm{c}}\end{array}$} & \multicolumn{6}{|c|}{ Website knowledge $(\mathrm{T} 3 ; \mathrm{n}=185)^{\mathrm{d}}$} \\
\hline & \multicolumn{2}{|c|}{ Model 1} & \multicolumn{2}{|c|}{ Model 2} & \multicolumn{2}{|c|}{ Model 1} & \multicolumn{2}{|c|}{ Model 2} & \multicolumn{2}{|c|}{ Model 1} & \multicolumn{2}{|c|}{ Model 2} & \multicolumn{2}{|c|}{ Model 3} \\
\hline & Beta & $P$ value & Beta & $P$ value & Beta & $P$ value & Beta & $P$ value & Beta & $P$ value & Beta & $P$ value & Beta & $P$ value \\
\hline \multicolumn{15}{|c|}{ Individual background characteristics } \\
\hline Age (years) & -0.23 & .001 & -0.23 & .001 & -0.08 & .26 & -0.04 & .59 & -0.18 & .02 & -0.08 & .23 & -0.08 & .24 \\
\hline $\begin{array}{l}\text { High education } \\
\text { level }\end{array}$ & 0.22 & .002 & 0.22 & .002 & -0.02 & .84 & -0.05 & .51 & 0.16 & .03 & 0.1 & .12 & 0.1 & .14 \\
\hline Internet use & -0.02 & .75 & -0.02 & .72 & $\mathrm{~L}^{\mathrm{e}}$ & - & - & - & 0.09 & .22 & 0.05 & .48 & 0.05 & .49 \\
\hline Coping style & 0.11 & .11 & 0.04 & .61 & - & - & - & - & - & - & - & - & - & - \\
\hline $\begin{array}{l}\text { Additional infor- } \\
\text { mation received }\end{array}$ & 0.13 & .05 & 0.1 & .11 & - & - & - & - & - & - & - & - & - & - \\
\hline Quality of life & - & - & - & - & - & - & - & - & -0.13 & .08 & -0.1 & .15 & -0.1 & .16 \\
\hline \multicolumn{15}{|c|}{ Website experience characteristics } \\
\hline $\begin{array}{l}\text { Website involve- } \\
\text { ment }\end{array}$ & - & - & 0.15 & .03 & - & - & - & - & - & - & - & - & - & - \\
\hline $\begin{array}{l}\text { Website attrac- } \\
\text { tiveness }\end{array}$ & - & - & -0.01 & .87 & - & - & 0.08 & .32 & - & - & - & - & - & - \\
\hline $\begin{array}{l}\text { Website compre- } \\
\text { hension }\end{array}$ & - & - & 0.15 & .05 & - & - & -0.02 & .78 & - & - & - & - & - & - \\
\hline Watched a video & - & - & 0.08 & .22 & - & - & 0.14 & .07 & - & - & - & - & - & - \\
\hline Knowledge (T1) & - & - & - & - & - & - & 0.22 & .003 & - & - & 0.39 & .001 & 0.39 & .001 \\
\hline $\begin{array}{l}\text { Website emotion- } \\
\text { al support }\end{array}$ & - & - & - & - & - & - & 0.07 & .36 & - & - & - & - & - & - \\
\hline $\begin{array}{l}\text { Communication } \\
\text { self-efficacy }\end{array}$ & - & - & - & - & - & - & 0.12 & .09 & - & - & - & - & - & - \\
\hline Time on website & - & - & - & - & - & - & 0.07 & .36 & - & - & 0.21 & .02 & 0.21 & .002 \\
\hline Anxiety (T1) & - & - & - & - & - & - & - & - & - & - & 0.04 & .52 & 0.04 & .52 \\
\hline \multicolumn{15}{|c|}{ Consultation experience characteristics } \\
\hline Question asking & - & - & - & - & - & - & - & - & - & - & - & - & 0 & .96 \\
\hline
\end{tabular}

${ }^{\mathrm{a}}$ Only variables marginally significant $(P<.10)$ that correlated with the predicted outcome variable were included. As no consultation characteristics correlated with information recall from the consultation (T3), only 2 models were predicted. Model 1 shows a simple linear regression model assessing the relationship between control variables and knowledge/information recall. Website experience characteristics were added to Model 2. Consultation experience was included in Model 3. We report the models without controlling for health literacy owing to missing data. Repeating the analyses with health literacy in the models did not change results, although health literacy significantly related to website knowledge (T3). $R^{2}$ indicates the adjusted explained variance of the model; $\Delta R^{2}$ shows the change in $R^{2}$ by adding predictors in Model 2 and 3; significant $\Delta F$ shows whether the difference in the $F$ value for model expansion is significant.

${ }^{\mathrm{b}}$ Adjusted $R^{2}$ Model 1=0.12, Model 2=0.17). Adding website experience characteristics to Model 2 improved the model $\left(\Delta R^{2}=0.06, P=.006\right)$.

${ }^{\mathrm{c}}$ Adjusted $R^{2}$ Model 1=0.00, Model 2=0.09). Adding website experience characteristics to Model 2 improved the model $\left(\Delta R^{2}=0.12, P=.001\right)$.

${ }^{\mathrm{d}}$ Adjusted $R^{2}$ Model $1=0.09$, Model $2=0.27$, Model 3=0.27). Adding website experience characteristics to Model 2 improved the model $\left(\Delta R^{2}=0.19\right.$, $P<.001)$. Addition consultation experience characteristics to Model 3 did not improve the model $\left(\Delta R^{2}=0.00, P=.96\right)$.

${ }^{\mathrm{e}}$ Not applicable.

\section{Discussion}

\section{Principal Findings}

This RCT tested the effectiveness of a mode-tailored preparatory website (ie, by self-selecting text, images, and/or videos) versus nontailored websites (ie, with either text only, text with images, or text with videos) in a clinical population of older ( $\geq 65$ years) and younger $(<65)$ patients visiting a fast-track clinic for diagnosis and treatment planning for colorectal, esophageal, or stomach cancer. The main research question was whether mode tailoring is more effective than nontailored information on patient-reported outcomes before, during, and after consultation. Moreover, we investigated whether older patients benefited proportionally more from mode-tailored information than younger patients. To advance theoretical models on information processing and the interplay between online information provision and offline patient-provider communication, we 
additionally explored which website experience outcomes and consultation experience outcomes contributed to patients' knowledge acquisition from online health information and information recall from consultations. Following is a review of the study results in light of the unexpected findings, discuss the implications for theory, and suggest directions for future research.

\section{Review of Findings}

The first main and unexpected finding of this study was that younger patients were more satisfied with the mode-tailored website (vs text only), whereas this was not the case for older patients. Moreover, younger patients who viewed the mode-tailored website reported lower anxiety levels immediately after consultation (vs text only). In contrast with our hypothesis, older patients reported higher anxiety in the mode-tailored condition (vs text only). Posthoc analyses revealed that younger patients also showed greater anxiety reduction from pre- to postconsultation, after viewing the mode-tailored website (vs the nontailored websites), whereas the anxiety levels of older patients in the mode-tailored condition remained the same. Both younger and older patients had equal anxiety levels before consultation. On the basis of the socioemotional selectivity theory, we expected that older patients would perceive more emotional gratification if they had the option to select information presented in visual/audiovisual modes, thereby limiting their anxiety. Alternatively, we now discuss a different explanation for our findings, from an uncertainty management theory perspective combined with the socioemotional selectivity theory. Generally speaking, younger adults are less tolerant to uncertainty than older adults [55] and, therefore, more likely to seek information as a strategy to reduce uncertainty [56,57]. It could be that, in our study, younger patients were more intolerant to the uncertainty that came with their cancer diagnosis and, therefore, exhausted all their information sources (ie, different information modes) to reduce uncertainty and, thereby, their anxiety. Older adults, on the contrary, are generally better at tolerating and managing uncertainty [55] and could be less urged to reduce it by means of information. Information might even have reversed effects and increase anxiety in this group, especially among older-old patients with cancer ( $\geq 70$ years), who more often prefer to leave information disclosure up to the health care provider [58]. Even though younger and older patients did not differ in information seeking/avoidance in this study, age-related differences in uncertainty tolerance might explain why providing information in tailored multiple modes particularly benefited younger patients, while it had no effect on older patients. The socioemotional selectivity theory also presents an explanation for this finding. Namely, younger adults pertain more to knowledge-related goals to prepare for future events, whereas older adults attach greater importance to emotionally meaningful goals [33]. It is possible that being able to view information in different (visual) modalities in a tailored manner accommodated to younger patients' information needs (ie, knowledge-related goals) and supported them in lowering their anxiety, which was less so for older patients. Future research is warranted to understand the role of uncertainty intolerance and information seeking/avoidance, as well as knowledge- versus emotional-related goals, in elucidating whether and how online tailored health information might accommodate the needs of and benefit younger and older patients with cancer.

Overall, we did not find that mode tailoring proportionally benefitted older patients more than younger patients. Possibly, older patients had more difficulty using the mode tailoring functionality, whereas this was more intuitive for younger patients, because of differences in internet experience (see Table 1). More long-term use and experience with the tailoring tool could make the mode-tailored website become beneficial for older patients as well. Alternatively, in our study sample, many patients were in their 60s (41.8\%). Despite the significant age difference of younger and older patients, many patients were aged around the cut-off of 65 years. This could explain why the age groups did not differ on age-related background variables and why no age differences were found in outcome variables. To illustrate, older patients in this study were not frailer than younger patients. In fact, the mean frailty score was 2.46 ( $S D$ $1.98)$, with less than a quarter of patients $(23.6 \%)$ reporting a score higher than 4, a cut-off used to identify patients as (moderately) frail [49]. Recent work found that age-related factors (eg, frailty, health literacy, and future time perspective) are more predictive of information recall from cancer websites than chronological age [40]. Moreover, older adults are a highly heterogeneous group in fundamental domains such as biological, cognitive, and personality characteristics [59], which could influence how online health information is used, processed, and evaluated [60]. Therefore, when investigating website use behaviors and intervention effects on patient outcomes, it might be meaningful to consider age-related variables as moderators of effects.

The second main finding of this study is that certain website experience outcomes (eg, website involvement and time spent on the website) increased patients' knowledge before and after the consultation. Higher previsit knowledge in turn supports patients in recalling information from the consultation. This suggests that offering information to help patients prepare for their hospital visit can improve past knowledge, which is important for how they process information during consultations, and remember this afterward. This is an important outcome, as knowledge is one of the key prerequisites for patients to be able to be involved in making treatment decisions and manage their illness [61]. Moreover, the website was widely used by patients across all website conditions (mean $34 \mathrm{~min}$ ), and this was not affected by age, gender, or education level. The majority of patients even used the website multiple times before their hospital visit. This underlines a desire for information before a hospital visit, perhaps even more so in emotionally charged contexts such as the diagnosis and treatment planning phase. What makes these findings particularly noteworthy is that in this study, we did not find a relationship between anxiety during consultation and information recall from the consultation. In a previous observational field study among the same patient population, at the same outpatient clinic, but without a preparatory website intervention, anxiety during consultation negatively predicted information recall from consultations [6]. Interestingly, in this RCT, anxiety was not found to be a barrier for information recall. A comparison between the 2 samples 
reveals that patients in both studies reported equally high anxiety levels. This raises the question: Could it be that offering patients' preparatory online information before their hospital visit helped them to attend to and process information from the consultation despite their anxiety levels? Previous studies showed that highly anxious patients with cancer have higher information needs [62] and that patients with fulfilled information needs are less anxious [63]. These findings, together with the results from our previous observational study and this RCT, suggest that knowledge (ie, by means of online health information) may play an important role in patients' anxiety management overall, especially for younger patients. However, to answer this question with more accuracy, future research is warranted to understand the added value of offering online preparatory information (vs no information) on patients' fulfillment of information needs, knowledge/information recall, and the anxiety-recall relationship.

Although no differences were found on main outcome variables, our data showed that patients spent more time on the mode-tailored website than on the nontailored website versions. This difference was not significant, but it suggests that mode tailoring may trigger patients to attend to the website information longer, which in this study proved to be important for knowledge acquisition from the website and information recall from consultations. The results align with earlier experimental findings that mode tailoring online information can increase attention to website information and consequently enhance information recall [17]. Although it is possible that the extra time spent on the mode-tailored website was because patients needed more time to figure out how the mode tailoring tool worked, it is more likely that patients spent this time viewing the website content. Namely, the time range that patients needed to select their first mode does not weigh up to the extra time patients spent on the mode-tailored website (vs the nontailored websites). Moreover, posthoc analyses revealed that viewing the mode-tailored website required comparable levels of cognitive effort as the nontailored versions for both younger and older patients (mean 2.65, SD 1.05; range 1-7 with higher scores indicating higher cognitive load, $F_{3,229}=0.23 ; P=.88$; $\eta \mathrm{p}^{2}=0.00$ ). In addition, even though no clear differences were found between conditions on the hypothesized outcome variables, the mode-tailored website kept patients online for a slightly longer period of time, which is likely to be important for knowledge gain. Together, the results suggest that offering online information to patients as a preparation tool might benefit patient outcomes.

\section{Theoretical Implications}

This study aimed to gain insight into which website experience outcomes and consultation experience outcomes explain the benefits of preparatory online information on knowledge acquisition from websites and information recall from consultations in the cancer communication context. As such, the results of this study are helpful in refining existing theoretical frameworks that conceptualize the interplay between mediated health communication and offline patient-provider communication in an eHealth era. At present, new information technologies open up a wide range of possibilities for patients to obtain health information outside of the consultation room. Scholars have conceptualized models of patient-provider communication that consider the role of mediated health communication to explain how communication can affect health outcomes via different pathways, such as by increasing patient knowledge, enhancing patients' ability to manage emotions, and enhancing patient empowerment and agency [64,65]. Although such overviews are a useful starting point, our findings help further specify which specific pathways, considering both online information provision and offline patient-provider communication, are key in improving patient health outcomes. Specifically, we identified variables related to attention (ie, time spent online) and website involvement as important motivational website experienceoutcomes that contribute to processing of online information, thereby increasing patients' knowledge. Although not one of the consultation experience outcomes (ie, question asking and anxiety) was related to information recall from consultations, we identified increased knowledge levels before consultation as an ability-related website experience outcome that benefitted patients' recall of information from the consultations. These results also inform future research relying on theories such as the ELM and LC4MP to understand which specific motivation- and ability-related factors play a role in how online cancer information is processed and how this may impact patient outcomes. This is important, as a critique on the ELM has been that its mediating variables are not clearly defined, leaving room for further specification of which variables contribute to motivation and ability to process information in different situational contexts [66]. We conclude with an integrated model visualizing how the use of online health information and patient-provider communication may lead to website experience outcomes and consultation experience outcomes, which may reinforce each other and ultimately explain knowledge and information recall (Figure 4). The process should be seen as a cycle, where each outcome can in turn influence the use of online health information and shape interactions between patients and providers. We note that this model is merely a starting point, and future research should complement this with relevant theoretical concepts that were unconsidered in our study.

This study also adds to the existing literature on computer-tailored health communication. Tailored online health information tools, typically providing recipients with content adapted to their individual characteristics, needs, and/or preferences have shown to be more effective than nontailored information on a wide range of patient outcomes, however typically with small effects [67-71]. Such tailored communication interventions may have provided personally relevant content but have possibly overlooked individual preferences for how this information should be presented. Moreover, the way in which content is processed highly depends on how this information is delivered [72]. Even though effects were small, this study suggests that tailoring the mode of information presentation to individual preferences, abilities, and/or learning styles could enhance the effectiveness of online health information interventions. Future research combining different tailoring strategies, such as content tailoring and mode tailoring, is warranted to tell whether effect sizes of tailored health communication interventions can be improved. 
Figure 4. Integrated model of website experience outcomes and consultation experience outcomes explaining knowledge/information recall.

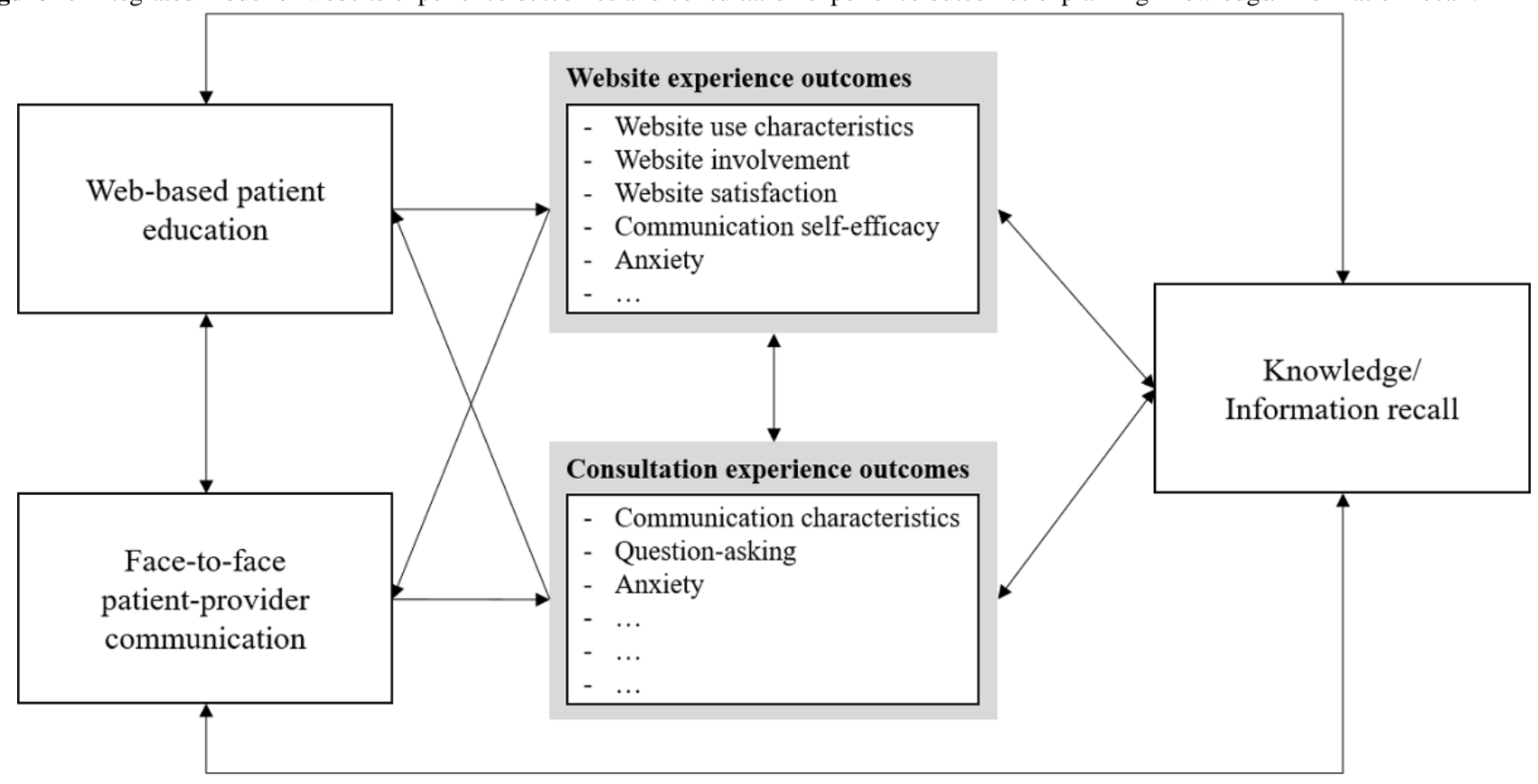

\section{Strengths, Limitations, and Future Research Directions}

This study is the first to translate mode tailoring research to a clinical population of patients with cancer. Major strengths are its longitudinal character (ie, following patients from before to during and after their hospital visit) and the combination of observational data (ie, website tracking data and video observations) and patient-reported outcomes. We were able to include over 240 patients in our trial, which is highly unique given the emotional burden that newly diagnosed patients with cancer experience and including patients at this stage is challenging. About half $(53.3 \%, 276 / 517)$ of patients declined participation. Although there was no age and gender difference between participating and nonparticipating patients, it is possible that those with varying education or health literacy levels were more or less likely to participate. Other RCTs employing educational interventions in cancer care report inclusion rates approximately between $25 \%$ and $60 \%$ [73-75]. Given that our inclusion rate was $47 \%$, we believe that our carefully crafted inclusion protocol made it possible to reach the desired sample size in a difficult-to-reach population (see the Methods section).

Previous tailoring studies examining modes of information presentation have been useful in identifying which message features yield effects on outcomes and in unraveling the theoretical mechanisms explaining these effects [17,18,76]. However, these findings must be translated to different clinical contexts to establish whether such interventions have added value in different real-life settings. Several null findings in this study, concerning website experience outcomes (eg, communication self-efficacy) and consultation-related outcomes (eg, question asking), cannot be compared with the previous research. Below we discuss possible reasons why mode tailoring did not produce similar effects in this study's clinical setting compared with previous experimental studies $[17,18]$.

The first explanation is the age discrepancy between our previous experimental work and this RCT. Younger patients, that is, those aged younger than 65 years, were for the greater part not represented in the experimental studies as they included younger adults between the ages of 25 and 45 years $[17,18]$. Moreover, as participants in the experimental studies were recruited via an online research panel, these older participants were likely to be healthier and have more internet experience than clinical older patients in this RCT.

The second explanation is the high topic involvement of patients and therefore high personal relevance of the website content, irrespective of how it was presented. The ELM suggests that information is more likely to be processed deeply when a person's interest for certain information is high, resulting in greater effects on outcomes (eg, information recall) [20]. Our sample consisted of newly diagnosed patients who were directed to a website about the specific clinic they were referred to, with information about their specific condition. Additionally, information avoiders might be underrepresented in our sample, as they might be less inclined to participate in our study. This might explain why the website was well used across all conditions (with only 9 patients not viewing the website) and why the perceived relevance of information did not differ between conditions. Consequently, it is possible that information was processed equally well from all website versions, revealing no differences in outcomes between conditions. Relatedly, it could be that some patients in the nontailored conditions received information in a way that coincidentally matched their preferences, attenuating effects of the mode-tailored website on outcomes. A previous tailoring study showed that when standardized information (by chance) corresponded to individual information needs, this was just as effective as tailored information [77]. Alternative explanations could be that the life-threatening nature of the disease (cancer), the emotionally charged moment (diagnosis), or a combination of these two elevated the perceived relevance and, consequently, website use. In this study, patients received the information while awaiting a final diagnosis and treatment plan, which is a phase in which information needs are the highest [26]. Future research 
could investigate whether mode tailoring has added value for clinical patients with a less life-threatening disease (eg, asthma, diabetes, and hypertension).

The third explanation is the uncontrolled setting of a field trial. In experimental studies, participants are exposed to stimulus materials, such as websites, and asked about these materials immediately afterward. In our field study, patients received a link to the website and the baseline questionnaire several days before their hospital visit. This allowed for patients to fill out the baseline questionnaire assessing website experience variables (eg, website satisfaction, anxiety, and communications self-efficacy) on different days before their visit. Moreover, patients varied in how often and how long they consulted the website. The variability concerning when their answers were recorded and how they used the website could have diluted the observable effects (eg, knowledge scores), if present. Although it would have been ideal to standardize study procedures even more, this is difficult, and perhaps unfruitful, in a clinical field study with patients with cancer.

In a similar vein, our sample consisted of a heterogeneous group of patients dealing with different cancer types (ie, colorectal, esophageal, or stomach cancer) with varying health trajectories before their appointment at the outpatient clinic. Although we imposed a strict randomization procedure that showed that patients did not differ on patient background characteristics, the sample heterogeneity could have attenuated the observable effects. We managed to recruit a relatively large sample for a difficult-to-reach clinical population, but it remains possible that we were unable to detect some of the hypothesized effects owing to a lack of statistical power. As a solution, qualitative approaches (eg, observations of or interviews with patients who have used the website intervention) might give a more meaningful and in-depth analysis of how the website was used, by whom, and whether this had added value for patients. This might be especially true for health communication interventions where small effect sizes are expected, and it remains difficult to obtain large, relatively homogeneous samples.

This study design did not include a no-information control group. A no-information control group would be useful to examine whether offering online preparatory information in general would have added value, but we considered that it would add little insight into mode tailoring effects. Furthermore, including a no-information control group would significantly reduce the number of patients in each condition given that data collection was limited to a maximum period of 3 years, further limiting statistical power to detect group differences. Although a no-information control group was not included, the results show that all the variables that predicted knowledge and recall were associated with the website (website involvement, website comprehension, and time spent on the website) and, therefore, imply that additional information sources surrounding the consultation can benefit patients.

In conclusion, we believe that there are many fruitful directions for future research. In addition to the suggestions we have already made, future research could for instance explore the relative importance of online information provision compared with offline, more traditional methods of information provision in different contexts and patient populations. To optimize information provision to all patients, researchers should continue to explore the added benefit of providing online preparatory information to patients (eg, in the form of hospital websites and patient portals), how specific features of the internet (eg, modality and interactivity) can be used to tailor information to patients, and whether different tailoring strategies (eg, content, mode, and cultural tailoring) are effective for patients regarding different types of patient outcomes (eg, evaluative, cognitive, psychosocial and behavioral) and in different patient populations (eg, high emotionally charged settings and non-life-threatening chronic diseases).

\section{Conclusions}

This RCT showed that higher use of online health information to prepare for consultations benefits patients' knowledge levels before a hospital visit. Higher knowledge, in turn, facilitates information processing and results in better information recall from medical consultations and knowledge acquisition from online information after their visit. Moreover, viewing online health information in a tailored presentation mode (ie, textual, visual, and/or audiovisual) increased younger patients' satisfaction with the health website and reduced their anxiety after consultation, but not for older patients. The results are important in refining existing theoretical frameworks of patient-provider communication in an eHealth era.

\section{Acknowledgments}

The authors thank all patients who participated in this study, the health care providers at the GIOCA for facilitating data collection, and all research assistants who helped collect the data. This study was funded by the Dutch Cancer Society (KWF Kankerbestrijding) under grant number UvA 2014-6700. KWF had no role in study design, data collection and analysis, decision to publish, or preparation of the manuscript.

\section{Conflicts of Interest}

None declared.

\section{References}

1. Pilleron S, Sarfati D, Janssen-Heijnen M, Vignat J, Ferlay J, Bray F, et al. Global cancer incidence in older adults, 2012 and 2035: a population-based study. Int J Cancer 2019 Jan 1;144(1):49-58. [doi: 10.1002/ijc.31664] [Medline: 29978474] 
2. Sparks L, Turner MM. The impact of cognitive and emotive communication barriers on older adult message processing of cancer-related health information: new directions for research. In: Sparks L, O'Hair H, Kreps G, editors. Cancer, Communication and Aging. New York: Hampton Press; 2008:17-47.

3. Butow PN, Dunn SM, Tattersall MH, Jones QJ. Patient participation in the cancer consultation: evaluation of a question prompt sheet. Ann Oncol 1994 Mar;5(3):199-204. [doi: 10.1093/oxfordjournals.annonc.a058793] [Medline: 8186168]

4. Maliski SL, Kwan L, Krupski T, Fink A, Orecklin JR, Litwin MS. Confidence in the ability to communicate with physicians among low-income patients with prostate cancer. Urology 2004 Aug;64(2):329-334. [doi: 10.1016/j.urology.2004.03.042] [Medline: 15302489$]$

5. Jansen J, Butow PN, van Weert JC, van Dulmen S, Devine RJ, Heeren TJ, et al. Does age really matter? Recall of information presented to newly referred patients with cancer. J Clin Oncol 2008 Nov 20;26(33):5450-5457. [doi: 10.1200/JCO.2007.15.2322] [Medline: 18936478]

6. Nguyen MH, Smets EM, Bol N, Bronner MB, Tytgat KM, Loos EF, et al. Fear and forget: how anxiety impacts information recall in newly diagnosed cancer patients visiting a fast-track clinic. Acta Oncol 2019 Feb;58(2):182-188. [doi: 10.1080/0284186X.2018.1512156] [Medline: $\underline{\text { 30264632] }}$

7. Medlock S, Eslami S, Askari M, Arts DL, Sent D, de Rooij SE, et al. Health information-seeking behavior of seniors who use the internet: a survey. J Med Internet Res 2015 Jan 8;17(1):e10 [FREE Full text] [doi: 10.2196/jmir.3749] [Medline: 25574815]

8. Luck A, Pearson S, Maddern G, Hewett P. Effects of video information on precolonoscopy anxiety and knowledge: a randomised trial. Lancet 1999 Dec 11;354(9195):2032-2035. [doi: 10.1016/s0140-6736(98)10495-6] [Medline: 10636368]

9. McMullan M. Patients using the internet to obtain health information: how this affects the patient-health professional relationship. Patient Educ Couns 2006 Oct;63(1-2):24-28. [doi: 10.1016/j.pec.2005.10.006] [Medline: 16406474]

10. Brandes K, Linn AJ, Butow PN, van Weert JC. The characteristics and effectiveness of question prompt list interventions in oncology: a systematic review of the literature. Psychooncology 2015 Mar;24(3):245-252. [doi: 10.1002/pon.3637] [Medline: 25082386]

11. van Weert JC, Jansen J, Spreeuwenberg PM, van Dulmen S, Bensing JM. Effects of communication skills training and a question prompt sheet to improve communication with older cancer patients: a randomized controlled trial. Crit Rev Oncol Hematol 2011 Oct;80(1):145-159. [doi: 10.1016/j.critrevonc.2010.10.010] [Medline: 21075644]

12. Bolle S, Romijn G, Smets EM, Loos EF, Kunneman M, van Weert JC. Older cancer patients' user experiences with web-based health information tools: a think-aloud study. J Med Internet Res 2016 Jul 25;18(7):e208 [FREE Full text] [doi: 10.2196/jmir.5618] [Medline: 27457709]

13. Friemel TN. The digital divide has grown old: determinants of a digital divide among seniors. New Media Soc 2014 Jun 12;18(2):313-331. [doi: 10.1177/1461444814538648]

14. Loos EF, Romano-Bergstrom J. Older adults. In: Romano-Bergstrom J, Schall AJ, editors. Eye Tracking in User Experience Design. Amsterdam: Elsevier; 2014:313-329.

15. Wright P, Soroka A, Belt S, Pham D, Dimov S, DeRoure D, et al. Modality preference and performance when seniors consult online information. Gerontechnology 2008;7(3):293-304. [doi: 10.4017/gt.2008.07.03.004.00]

16. Smit ES, Linn AJ, van Weert JC. Taking online computer-tailoring forward: the potential of tailoring the message frame and delivery mode of online health behaviour change interventions. Eur Health Psychol 2015;17(1):25-31 [FREE Full text]

17. Nguyen MH, van Weert JC, Bol N, Loos EF, Tytgat KM, van de Ven AW, et al. Tailoring the mode of information presentation: effects on younger and older adults' attention and recall of online information. Hum Commun Res 2016 Oct 21;43(1):102-126. [doi: 10.1111/hcre.12097]

18. Nguyen MH, Smets EM, Bol N, Loos EF, van Weert JC. How tailoring the mode of information presentation influences younger and older adults' satisfaction with health websites. J Health Commun 2018;23(2):170-180. [doi: 10.1080/10810730.2017.1421729] [Medline: 29345531]

19. Lang A. Using the limited capacity model of motivated mediated message processing to design effective cancer communication messages. J Commun 2006 Aug;56(s1):S57-S80 [FREE Full text] [doi: 10.1111/j.1460-2466.2006.00283.x]

20. Petty R, Barden J, Wheeler S. The elaboration likelihood model of persuasion: health promotions that yield sustained behavior change. In: DiClemente RJ, Crosby RA, Kegler MC, editors. Emerging Theories in Health Promotion Practice and Research. San Fransisco: Jossey-Bass; 2002:71-99.

21. Bodie GD, Dutta MJ. Understanding health literacy for strategic health marketing: ehealth literacy, health disparities, and the digital divide. Health Mark Q 2008;25(1-2):175-203. [doi: 10.1080/07359680802126301] [Medline: 18935884]

22. Rideout V, Neuman T, Kitchman M, Brodie M. Kaiser Family Foundation. 2005. e-Health and the Elderly: How Seniors Use the Internet for Health Information URL: https://www.kff.org/wp-content/uploads/2013/01/ e-health-and-the-elderly-how-seniors-use-the-internet-for-health-information-key-findings-from-a-national-survey-of-older-americans-survey-report. pdf [accessed 2017-03-30] [WebCite Cache ID 6pLm4uZzn]

23. Becker SA. A study of web usability for older adults seeking online health resources. ACM Trans Comput-Hum Interact 2004 Dec 1;11(4):387-406. [doi: 10.1145/1035575.1035578] 
24. Bronner MB, Nguyen MH, Smets EM, van de Ven AW, van Weert JC. Anxiety during cancer diagnosis: examining the influence of monitoring coping style and treatment plan. Psychooncology 2018 Feb;27(2):661-667. [doi: 10.1002/pon.4560] [Medline: 28976610]

25. Rees CE, Bath PA. Information-seeking behaviors of women with breast cancer. Oncol Nurs Forum 2001 Jun;28(5):899-907. [Medline: 11421149$]$

26. Rutten LJ, Arora NK, Bakos AD, Aziz N, Rowland J. Information needs and sources of information among cancer patients: a systematic review of research (1980-2003). Patient Educ Couns 2005 Jun;57(3):250-261. [doi: 10.1016/j.pec.2004.06.006] [Medline: $\underline{15893206]}$

27. Nguyen MH, Bol N, van Weert JC, Loos EF, Tytgat KM, Geijsen D, et al. Optimising ehealth tools for older patients: collaborative redesign of a hospital website. Eur J Cancer Care (Engl) 2019 Jan;28(1):e12882 [FREE Full text] [doi: 10.1111/ecc.12882] [Medline: $\underline{30015998]}$

28. Albada A, van Dulmen S, Lindhout D, Bensing JM, Ausems MG. A pre-visit tailored website enhances counselees' realistic expectations and knowledge and fulfils information needs for breast cancer genetic counselling. Fam Cancer 2012 Mar;11(1):85-95. [doi: 10.1007/s10689-011-9479-1] [Medline: 21901499]

29. Jerant A, Sohler N, Fiscella K, Franks B, Franks P. Tailored interactive multimedia computer programs to reduce health disparities: opportunities and challenges. Patient Educ Couns 2011 Nov;85(2):323-330 [FREE Full text] [doi: 10.1016/j.pec.2010.11.012] [Medline: 21146950]

30. Street Jr RL, Slee C, Kalauokalani DK, Dean DE, Tancredi DJ, Kravitz RL. Improving physician-patient communication about cancer pain with a tailored education-coaching intervention. Patient Educ Couns 2010 Jul;80(1):42-47 [FREE Full text] [doi: 10.1016/j.pec.2009.10.009] [Medline: 19962845]

31. Linn AJ, van Weert JC, Smit EG, Perry K, van Dijk L. 1+1=3? The systematic development of a theoretical and evidence-based tailored multimedia intervention to improve medication adherence. Patient Educ Couns 2013 Dec;93(3):381-388. [doi: 10.1016/j.pec.2013.03.009] [Medline: 23579041]

32. Iverson SA, Howard KB, Penney BK. Impact of internet use on health-related behaviors and the patient-physician relationship: a survey-based study and review. J Am Osteopath Assoc 2008 Dec;108(12):699-711. [doi: 10.7556/jaoa.2008.108.12.699] [Medline: 19075034]

33. Löckenhoff CE, Carstensen LL. Socioemotional selectivity theory, aging, and health: the increasingly delicate balance between regulating emotions and making tough choices. J Pers 2004 Dec;72(6):1395-1424. [doi:

10.1111/j.1467-6494.2004.00301.x] [Medline: 15509287]

34. Ogozalek VZ. A Comparison of the Use of Text and Multimedia Interfaces to Provide Information to the Elderly. In: Proceedings of the SIGCHI Conference on Human Factors in Computing Systems. 1994 Presented at: CHI'94; April 24-28, 1994; Boston, Massachusetts, USA p. 65-71. [doi: 10.1145/191666.191700]

35. Bol N, Smets EM, Eddes EH, de Haes JC, Loos EF, van Weert JC. Illustrations enhance older colorectal cancer patients' website satisfaction and recall of online cancer information. Eur J Cancer Care (Engl) 2015 Mar;24(2):213-223. [doi: 10.1111/ecc.12283] [Medline: 25615269]

36. Bol N, Smets EM, Rutgers MM, Burgers JA, de Haes HC, Loos EF, et al. Do videos improve website satisfaction and recall of online cancer-related information in older lung cancer patients? Patient Educ Couns 2013 Sep;92(3):404-412. [doi: 10.1016/j.pec.2013.06.004] [Medline: 23820196]

37. Soroka AJ, Wright P, Belt S, Pham DT, Dimov SS, de Roure D, et al. User Choices for Modalities of Instructional Information. In: Proceedings of the 4th IEEE International Conference on Industrial Informatics. 2006 Presented at: INDIN'06; August 16-18, 2006; Singapore, Singapore p. 411-416. [doi: 10.1109/INDIN.2006.275835]

38. Kessels RP. Patients' memory for medical information. J R Soc Med 2003 May;96(5):219-222 [FRE Full text] [doi: 10.1258/jrsm.96.5.219] [Medline: 12724430]

39. Posma ER, van Weert JC, Jansen J, Bensing JM. Older cancer patients' information and support needs surrounding treatment: an evaluation through the eyes of patients, relatives and professionals. BMC Nurs 2009 Jan 19;8:1 [FREE Full text] [doi: 10.1186/1472-6955-8-1] [Medline: 19152675]

40. Bol N, Smets EM, Burgers JA, Samii SM, de Haes HC, van Weert JC. Older patients' recall of online cancer information: do ability and motivation matter more than chronological age? J Health Commun 2018;23(1):9-19. [doi: 10.1080/10810730.2017.1394400] [Medline: 29227736]

41. Basta YL, Baur O, van Dieren DS, Klinkenbijl JH, Fockens P, Tytgat KM. Is there a benefit of multidisciplinary cancer team meetings for patients with gastrointestinal malignancies? Ann Surg Oncol 2016 Aug;23(8):2430-2437 [FREE Full text] [doi: 10.1245/s10434-016-5178-3] [Medline: 27002814]

42. Dutta-Bergman MJ. The impact of completeness and web use motivation on the credibility of e-health information. $\mathrm{J}$ Commun 2004;54(2):253-269. [doi: 10.1111/j.1460-2466.2004.tb02627.x]

43. Bol N, van Weert JC, de Haes HC, Loos EF, de Heer S, Sikkel D, et al. Using cognitive and affective illustrations to enhance older adults' website satisfaction and recall of online cancer-related information. Health Commun 2014;29(7):678-688. [doi: 10.1080/10410236.2013.771560] [Medline: 24160560] 
44. ten Klooster KP, Oostveen JC, Zandbelt LC, Taal E, Drossaert CH, Harmsen EJ, et al. Further validation of the 5-item perceived efficacy in patient-physician interactions (PEPPI-5) scale in patients with osteoarthritis. Patient Educ Couns 2012 Apr;87(1):125-130. [doi: 10.1016/j.pec.2011.07.017] [Medline: 21889864]

45. Marteau TM, Bekker H. The development of a six-item short-form of the state scale of the Spielberger state-trait anxiety inventory (STAI). Br J Clin Psychol 1992 Sep;31(Pt 3):301-306. [doi: 10.1111/j.2044-8260.1992.tb00997.x] [Medline: 1393159]

46. Millar K, Jelicic M, Bonke B, Asbury AJ. Assessment of preoperative anxiety: comparison of measures in patients awaiting surgery for breast cancer. Br J Anaesth 1995 Feb;74(2):180-183 [FREE Full text] [doi: 10.1093/bja/74.2.180] [Medline: 7696068]

47. Jansen J, van Weert JC, van der Meulen N, van Dulmen S, Heeren T, Bensing JM. Recall in older cancer patients: measuring memory for medical information. Gerontologist 2008 Apr;48(2):149-157. [doi: 10.1093/geront/48.2.149] [Medline: 18483427]

48. Zandbelt LC, Smets EM, Oort FJ, Godfried MH, de Haes HC. Medical specialists' patient-centered communication and patient-reported outcomes. Med Care 2007 Apr;45(4):330-339. [doi: 10.1097/01.mlr.0000250482.07970.5f] [Medline: 17496717]

49. Maat HP, Essink-Bot ML, Leenaars KE, Fransen MP. A short assessment of health literacy (SAHL) in the Netherlands. BMC Public Health 2014 Sep 23;14:990 [FREE Full text] [doi: 10.1186/1471-2458-14-990] [Medline: 25246170]

50. Steverink N, Slaets J, Schuurmans H, van Lis M. Measuring frailty: development and testing of the Groningen frailty indicator (GFI). Gerontologist 2001;41(1):236-237 [FREE Full text]

51. Aaronson NK, Ahmedzai S, Bergman B, Bullinger M, Cull A, Duez NJ, et al. The European Organization for Research and Treatment of Cancer QLQ-C30: a quality-of-life instrument for use in international clinical trials in oncology. J Natl Cancer Inst 1993 Mar 3;85(5):365-376. [doi: 10.1093/jnci/85.5.365] [Medline: $\underline{\text { 8433390] }}$

52. Miller SM. Monitoring and blunting: validation of a questionnaire to assess styles of information seeking under threat. J Pers Soc Psychol 1987 Feb;52(2):345-353. [doi: 10.1037/0022-3514.52] [Medline: 3559895]

53. Thomas R, Kaminski E, Stanton E, Williams M. Measuring information strategies in oncology - developing an information satisfaction questionnaire. Eur J Cancer Care (Engl) 2004 Mar;13(1):65-70. [doi: 10.1111/j.1365-2354.2004.00445.x] [Medline: 14961777]

54. van Weert JC, Jansen J, de Bruijn GJ, Noordman J, van Dulmen S, Bensing JM. QUOTEchemo: a patient-centred instrument to measure quality of communication preceding chemotherapy treatment through the patient's eyes. Eur J Cancer 2009 Nov;45(17):2967-2976. [doi: 10.1016/j.ejca.2009.06.001] [Medline: 19615889]

55. Basevitz P, Pushkar D, Chaikelson J, Conway M, Dalton C. Age-related differences in worry and related processes. Int J Aging Hum Dev 2008;66(4):283-305. [doi: 10.2190/AG.66.4.b] [Medline: 18507331]

56. Carcioppolo N, Yang F, Yang Q. Reducing, maintaining, or escalating uncertainty? The development and validation of four uncertainty preference scales related to cancer information seeking and avoidance. J Health Commun 2016 Sep;21(9):979-988. [doi: 10.1080/10810730.2016.1184357] [Medline: 27450905]

57. Miller LE. Uncertainty management and information seeking in cancer survivorship. Health Commun 2014;29(3):233-243. [doi: 10.1080/10410236.2012.739949] [Medline: 23682727]

58. Jenkins V, Fallowfield L, Saul J. Information needs of patients with cancer: results from a large study in UK cancer centres. Br J Cancer 2001 Jan 5;84(1):48-51 [FREE Full text] [doi: 10.1054/bjoc.2000.1573] [Medline: 11139312]

59. Stone ME, Lin J, Dannefer D, Kelley-Moore JA. The continued eclipse of heterogeneity in gerontological research. J Gerontol B Psychol Sci Soc Sci 2017 Jan;72(1):162-167 [FREE Full text] [doi: 10.1093/geronb/gbv068] [Medline: 26834089]

60. van der Goot M. Older adults' mediated communication: current perspectives among communication scholars. In: Nussbaum J, editor. Communication Across the Lifespan. New York: Peter Lang; 2016:79-89.

61. Elwyn G, Frosch D, Thomson R, Joseph-Williams N, Lloyd A, Kinnersley P, et al. Shared decision making: a model for clinical practice. J Gen Intern Med 2012 Oct;27(10):1361-1367 [FREE Full text] [doi: 10.1007/s11606-012-2077-6] [Medline: 22618581]

62. Davison BJ, Breckon E. Factors influencing treatment decision making and information preferences of prostate cancer patients on active surveillance. Patient Educ Couns 2012 Jun;87(3):369-374. [doi: 10.1016/j.pec.2011.11.009] [Medline: 22177658]

63. Husson O, Mols F, van de Poll-Franse LV. The relation between information provision and health-related quality of life, anxiety and depression among cancer survivors: a systematic review. Ann Oncol 2011 Apr;22(4):761-772 [FREE Full text] [doi: 10.1093/annonc/mdq413] [Medline: 20870912]

64. Street Jr RL. Mediated consumer-provider communication in cancer care: the empowering potential of new technologies. Patient Educ Couns 2003 May;50(1):99-104. [doi: 10.1016/S0738-3991(03)00089-2] [Medline: 12767594]

65. Street Jr RL, Makoul G, Arora NK, Epstein RM. How does communication heal? Pathways linking clinician-patient communication to health outcomes. Patient Educ Couns 2009 Mar;74(3):295-301. [doi: 10.1016/j.pec.2008.11.015] [Medline: 19150199]

66. Kitchen PJ, Kerr G, Schultz DE, McColl R, Pals H. The elaboration likelihood model: review, critique and research agenda. Eur J Mark 2014 Nov 4;48(11/12):2033-2050. [doi: 10.1108/EJM-12-2011-0776] 
67. Krebs P, Prochaska JO, Rossi JS. A meta-analysis of computer-tailored interventions for health behavior change. Prev Med 2010;51(3-4):214-221 [FREE Full text] [doi: 10.1016/j.ypmed.2010.06.004] [Medline: 20558196]

68. Lustria ML, Noar SM, Cortese J, van Stee SK, Glueckauf RL, Lee J. A meta-analysis of web-delivered tailored health behavior change interventions. J Health Commun 2013;18(9):1039-1069. [doi: 10.1080/10810730.2013.768727] [Medline: 23750972]

69. Noar SM, Benac CN, Harris MS. Does tailoring matter? Meta-analytic review of tailored print health behavior change interventions. Psychol Bull 2007 Jul;133(4):673-693. [doi: 10.1037/0033-2909.133.4.673] [Medline: 17592961]

70. Portnoy DB, Scott-Sheldon LA, Johnson BT, Carey MP. Computer-delivered interventions for health promotion and behavioral risk reduction: a meta-analysis of 75 randomized controlled trials, 1988-2007. Prev Med 2008 Jul;47(1):3-16 [FREE Full text] [doi: 10.1016/j.ypmed.2008.02.014] [Medline: 18403003]

71. Sohl SJ, Moyer A. Tailored interventions to promote mammography screening: a meta-analytic review. Prev Med 2007 Oct;45(4):252-261 [FREE Full text] [doi: 10.1016/j.ypmed.2007.06.009] [Medline: 17643481]

72. Ritterband LM, Thorndike FP, Cox DJ, Kovatchev BP, Gonder-Frederick LA. A behavior change model for internet interventions. Ann Behav Med 2009 Aug;38(1):18-27 [FREE Full text] [doi: 10.1007/s12160-009-9133-4] [Medline: 19802647]

73. Albada A, van Dulmen S, Spreeuwenberg P, Ausems MG. Follow-up effects of a tailored pre-counseling website with question prompt in breast cancer genetic counseling. Patient Educ Couns 2015 Jan;98(1):69-76. [doi:

10.1016/j.pec.2014.10.005] [Medline: 25455796]

74. Yun YH, Lee KS, Kim YW, Park SY, Lee ES, Noh DY, et al. Web-based tailored education program for disease-free cancer survivors with cancer-related fatigue: a randomized controlled trial. J Clin Oncol 2012 Apr 20;30(12):1296-1303. [doi: 10.1200/JCO.2011.37.2979] [Medline: 22412149]

75. Willems RA, Bolman CA, Mesters I, Kanera IM, Beaulen AA, Lechner L. Short-term effectiveness of a web-based tailored intervention for cancer survivors on quality of life, anxiety, depression, and fatigue: randomized controlled trial. Psychooncology 2017 Feb;26(2):222-230. [doi: 10.1002/pon.4113] [Medline: 26988800]

76. Jensen JD, King AJ, Carcioppolo N, Davis L. Why are tailored messages more effective? A multiple mediation analysis of a breast cancer screening intervention. J Commun 2012 Oct;62(5):851-868 [FREE Full text] [doi:

10.1111/j.1460-2466.2012.01668.x] [Medline: 26405350]

77. Kreuter MW, Oswald DL, Bull FC, Clark EM. Are tailored health education materials always more effective than non-tailored materials? Health Educ Res 2000 Jun;15(3):305-315. [doi: 10.1093/her/15.3.305] [Medline: 10977378]

\section{Abbreviations}

ELM: elaboration likelihood model

GIOCA: Gastro-Intestinal Oncological Centre Amsterdam

LC4MP: limited capacity model of motivated mediated message processing

NPIRQ: Netherlands Patient Information Recall Questionnaire

RCT: randomized controlled trial

STAI-6: 6-item version of the State-Trait Anxiety Inventory

Edited by G Eysenbach; submitted 16.04.19; peer-reviewed by J Noordman, T Dekkers, C Hoving; comments to author 07.06.19;
revised version received 12.07.19; accepted 19.07.19; published 01.10.19
Please cite as:
Nguyen MH, Smets EMA, Bol N, Loos EF, van Laarhoven HWM, Geijsen D, van Berge Henegouwen MI, Tytgat KMAJ, van Weert
JCM
Tailored Web-Based Information for Younger and Older Patients with Cancer: Randomized Controlled Trial of a Preparatory
Educational Intervention on Patient Outcomes
J Med Internet Res $2019 ; 21(10):$ el 14407
URL: $\underline{\text { https://www.jmir.org/2019/10/e14407 }}$
doi: $\underline{10.2196 / 14407}$
PMID: $\underline{31573911}$

(CMinh Hao Nguyen, Ellen MA Smets, Nadine Bol, Eugène F Loos, Hanneke WM van Laarhoven, Debby Geijsen, Mark I van Berge Henegouwen, Kristien MAJ Tytgat, Julia CM van Weert. Originally published in the Journal of Medical Internet Research (http://www.jmir.org), 01.10.2019 This is an open-access article distributed under the terms of the Creative Commons Attribution License (https://creativecommons.org/licenses/by/4.0/), which permits unrestricted use, distribution, and reproduction in any medium, provided the original work, first published in the Journal of Medical Internet Research, is properly cited. The complete 
bibliographic information, a link to the original publication on http://www.jmir.org/, as well as this copyright and license information must be included. 